\title{
Hedonic Valuation with Translating Amenities: Mountain Pine Beetles and Host Trees in the Colorado Front Range
}

\author{
Jed Cohen • Christine E. Blinn • Kevin J. Boyle • \\ Thomas P. Holmes · Klaus Moeltner
}

Accepted: 15 December 2014 / Published online: 31 December 2014

C Springer Science+Business Media Dordrecht 2014

\begin{abstract}
In hedonic valuation studies the policy-relevant environmental quality attribute of interest is often costly to measure, especially under pronounced spatial and temporal variability. However, in many cases this attribute affects home prices and consumer preferences solely through its impact on a readily observable, spatially delineated, and time-invariant feature of the physical landscape. We label such a feature a "translating amenity." We show that under certain conditions changes in the marginal effect of such amenities on home values over time can be used to draw inference on the implicit price of the unobserved environmental quality of interest. We illustrate this approach in the context of a repeat-sales model and the recently intensified outbreak of the Mountain Pine Beetle in the Colorado Front Range.
\end{abstract}

Keywords Forest pests · Property values - Repeat-sales model · Wildland-urban interface

We thank seminar participants at the 2013 Meetings of the W3133 Western Regional Science Project (Coeur d' Alene, ID, Feb. 27-March 2), and the US Airforce Academy, Colorado Springs (March 15, 2013), for insightful and stimulating comments. Funding provided by the Southern Research Station, USDA Forest Service, is gratefully acknowledged.

J. Cohen · K. J. Boyle $\cdot$ K. Moeltner $(\varangle)$

Department of Agricultural and Applied Economics, Virginia Tech, 208 Hutcheson Hall,

Blacksburg, VA 24061, USA

e-mail: moeltner@vt.edu

J. Cohen

e-mail: jedcohen@vt.edu

K. J. Boyle

e-mail: kjboyle@vt.edu

C. E. Blinn

Department of Forest Resources and Environmental Conservation, Virginia Tech, Blacksburg, USA

e-mail: cblinn@vt.edu

T. P. Holmes

USDA Forest Service, Southern Research Station, Research Triangle Park, NC, USA

e-mail: tholmes@fs.fed.us 


\section{Introduction}

The primary aim in many hedonic valuation studies is to estimate the marginal effect of an environmental quality attribute, say $q$, on observed home prices. As discussed in numerous sources (e.g. Palmquist 1991; Freeman 2003; Palmquist 2005) under standard assumptions governing the housing market under consideration, this marginal effect can be interpreted as "implicit price" or "marginal willingness-to-pay (WTP)" by the home owner for a incremental change in $q$.

The focus on $q$ usually arises from policy considerations targeting its regulation or changes in its ambient levels. Prominent examples include Total Maximum Daily Loads (TMDLs) for specific pollutants and water bodies (e.g. US Environmental Protection Agency 2014a,d), imposed standards for air pollution (e.g. US Environmental Protection Agency 2014b, c), or noise abatement rules for airports and traffic arteries (e.g. Federal Highway Administration 2014). However, in many practical hedonic applications it can be difficult or costly to measure property-specific levels of $q$. Most existing studies have circumvented this issue by assigning homes to "nearest measuring points" or "common quality zones" for the environmental attribute of interest (e.g. Palmquist 1982; Leggett and Bockstael 2000; Kim et al. 2003; Neill et al. 2007; Anselin and Lozano-Gracia 2008; Pope 2008; Boyle et al. 2010). While these aggregate exposure models generally produce plausible results they do pose the risk of measurement error if this implicit assumption of homogeneous quality for (often large) clusters of homes is violated for a substantial share of individual properties in the sample. Naturally, such measurement problems are aggravated in multi-period applications if $q$ changes in magnitude over time, and if there are temporal holes in its measurement in addition to lacking spatial specificity.

In this study we consider a low-cost alternative to the valuation of $q$ in a hedonic framework that has been implicitly used in a small set of existing contributions, but never theoretically motivated or formalized. It is based on the concept of Translating Amenities (TAs), which we define to be time-invariant features of the landscape that are property-specific, straightforward to measure using modern GIS tools, and intrinsically linked to the environmental attribute of primary interest. For example, Cho et al. (2011) use the Euclidean distance to the nearest impaired portion of a river to measure the impact of water pollution from a pulp and paper mill on home values. In this case, the policy-relevant variable from the perspective of a regulating agency is the unobserved water quality, and the TA is the river segment itself. A similar approach is taken by Kovacs et al. (2011), who use home-specific distances to live oak woodland (the TA), as well as binary indicators for the presence or absence of such woodlands within different perimeters of a given residence to estimate the effect of sudden oak death infestations (the policy-relevant environmental quality) on local housing markets.

There does not yet exist a structural motivation for the use of such TAs to capture homeowners' preferences for unobserved (or scientifically un-measured) environmental quality. This paper aims to fill this gap. We provide a theoretical outline of the Translating Amenity Method (TAM), and draw parallels to the concept of weak complementarity in recreation demand studies. Specifically, we illustrate that for the TAM to yield valid estimates of underlying environmental quality effects, the following two critical assumptions must hold: (i) The TA matters to residents (i.e. enters utility functions and hedonic price surfaces), and (ii) constitutes the sole link between the policy-relevant amenity $q$ and consumer preferences for housing. In other words, in absence of the TA, the effect of $q$ on property values is zero. We show that under these assumptions and within the framework of a Repeat Sales Model (RSM) the marginal effect of the TA on differenced home prices can be directly related to the implicit price of $q$ for standard specifications of the hedonic price function. 
We apply the method to an ongoing environmental resource change of epic proportions: The massive and widespread infestation of forestlands by the Mountain Pine Beetle (MPB) in large parts of the US and Canadian west. Focusing on two counties in the Colorado Front Range, we show that the MPB impact can be estimated using host trees as translating commodity, following the implicit strategy of Kovacs et al. (2011). We find that accumulated losses in home values amount to hundreds of millions of dollars for properties in the host tree zone. This has significant impacts on property taxes, and thus the fiscal viability of local communities.

The remainder of this paper is structured as follows: in the next section we outline the theoretical underpinnings of the TAM. This is followed by an econometric exposition on incorporating the TAM in an RSM. Section 4 discusses the data and presents estimation results. Section 5 concludes.

\section{Conceptual Framework}

As is conventionally assumed, a local resident derives utility from the purchase of a single property and a numeraire commodity $z$. As in Phaneuf et al. (2008) we further stipulate that home and neighborhood features $\mathbf{x}$, as well as a policy-relevant environmental amenity $q$ enter utility via a housing function $H$ (.). In our case, $q$ enters the housing function, and thus utility, via a translating function $f$ (.) that combines $q$ with a translating amenity $h$. The consumer's optimization problem in period $t$ can then be stated as follows:

$$
\max _{\mathbf{x}, q, z} U(H(\mathbf{x}, f(h, q ; \boldsymbol{\theta})), z ; \boldsymbol{\gamma}) \quad \text { s.t. } \quad y=P(f(h, q ; \boldsymbol{\theta}), \mathbf{x} ; \boldsymbol{\delta})+z,
$$

where $\boldsymbol{\gamma}$ and $\boldsymbol{\theta}$ are vectors of preference parameters, $y$ is household income, $P$ is the price of a given residence, and $\delta$ is a vector of parameters for the reduced-form price function $P$ (.) that governs a specific housing market. ${ }^{1}$ Specifically, $\boldsymbol{\gamma}$ collects preference parameters related to housing attributes $\mathbf{x}$, while $\boldsymbol{\theta}$ captures preferences related to environmental quality $q$ and translating amenity $h$.

The first order conditions then lead to the well-known equality of currency-valued marginal benefits of $q$, and $q$ 's marginal contribution to home price:

$$
\frac{\frac{\partial U(.)}{\partial q}}{\frac{\partial U(.)}{\partial z}}=\frac{\frac{\partial U(.)}{\partial H(.)} \frac{\partial H(.)}{\partial f(.)} \frac{\partial f(.)}{\partial q}}{\frac{\partial U(.)}{\partial z}}=\frac{\partial P(.)}{\partial f(.)} \frac{\partial f(.)}{\partial q}=\frac{\partial P(.)}{\partial q}
$$

For the TAM to be valid, we need

$$
\left(\frac{\partial U(.)}{\partial q} \mid h=0\right)=0
$$

That is, if there are no TA's in the vicinity of a given home $(h=0)$, environmental quality $q$ has no further effect on utility. This holds if $q$ enters utility only via the translating function

\footnotetext{
${ }^{1}$ To be clear, Phaneuf et al. (2008) specify utility as $U=U(x(q), h(\mathbf{a}, q), z, \epsilon)$, where $h($.$) is the housing$ function, $\mathbf{a}$ is a vector of housing attributes, and $\epsilon$ denotes unobserved heterogeneity. The term $x(q)$ refers to local recreational opportunities, which are not relevant in our case. Our notation also differs in that we label the housing function as $H($.$) , and the housing attributes as \mathbf{x}$. We also include preference parameters $(\boldsymbol{\gamma}$ and $\boldsymbol{\theta}$ ), which are not explicitly captured in their specification. In contrast, unobserved heterogeneity does not play a major role in our context, so their error term $\epsilon$ is absent from our model. However, both models include environmental quality $q$ and the numeraire commodity $z$.
} 
$f($.$) , and if, in addition,$

$$
\frac{\partial f(0, q, \boldsymbol{\theta})}{\partial q}=0
$$

If condition (3) is violated, the TA will not capture the full implicit price of $q$, as will be clear from the following exposition. Condition (4) requires for $q$ and $h$ to interact in the translating function such that in absence of the translating good $h$, the environmental amenity $q$ vanishes from $f($.$) , and thus from both the utility function and the price surface. This requirement$ is akin to the "weak complementarity" condition in recreation demand studies, where the effect of the environmental amenity $q$ on utility disappears when demand for a linked market good (trips or visits to a recreation site) drops to zero. As discussed in von Haefen (2007), numerous empirical approaches are possible to implement this condition.

By analogy, there are several ways to specify $f($.) to assure that $q$ becomes ineffective in absence of $h$. Meaningful specifications likely depend on the individual context. We will thus cast the further development of our model within the framework of our empirical application. In our case, $q$ denotes some measurement of Mountain Pine Beetle (MPB) density (e.g. beetles per tree section) within a specific perimeter of a private residence. It is the policy variable of interest in the sense that potential mitigating actions would be targeted directly towards a reduction of the beetle population.

The MPB needs host trees to survive (ponderosa, white, lodgepole, and other pines). The health—and thus look—of host trees, in turn, is likely to affect homeowners' utility and property values. We thus let our translating commodity be $h$, the number of host trees (or, alternatively, the combined biomass of host trees) within the same perimeter of a given residence. We then specify the translating function $f($.$) as$

$$
f(h, q, \boldsymbol{\theta})=\theta_{1} \alpha(q) h+\theta_{2}(1-\alpha(q)) h, \quad 0 \leq \alpha(q) \leq 1,
$$

where $\alpha$ (.) is a damage function that converts MPB density into the proportion of diseased trees (or biomass). Thus, $\alpha(q) h$ captures the number of diseased trees within the specified perimeter, and $(1-\alpha(q)) h$ indicates the number of healthy trees. ${ }^{2}$ The terms $\theta_{1}$ and $\theta_{2}$ are the corresponding preferences for, respectively, sick and healthy trees, which are assumed common to all homeowners. Other than satisfying the linkage constraint in (4), this specification of $f($.$) allows for asymmetric preferences based on tree health-for example, homeowners$ likely cherish healthy trees (or are, at worst, indifferent), but dislike diseased trees (or are, at best, indifferent). We believe that the distinction between homeowners' preferences for undisturbed and impacted portions of $h$ is important as it corresponds well to many realistic applications. For example, a noise-generating nearby highway may nonetheless provide quick access to work and shopping, and a polluted lake or stream may still allow for some boating or fishing. Thus, the specification of the translating function in (5) is quite general. ${ }^{3}$

The implicit price of $q$ is then given as

$$
\frac{\partial P(.)}{\partial q}=\frac{\partial P(.)}{\partial f(.)} \frac{\partial f(.)}{\partial q}=\frac{\partial P(.)}{\partial f(.)}\left(\theta_{1}-\theta_{2}\right) \alpha^{\prime}(q) h=\beta(q) h
$$

\footnotetext{
2 If the relevant policy intervention directly targets trees instead of beetles, for example via the removal of diseased pines, $\alpha(q)$ simplifies to $\alpha$. In that case $q$ would be the number or biomass of dead trees, and host trees at large would still be the TA.

3 This is why $h$ is not a proxy variable in a formal econometric sense, as it can still influence home values independently of the unobserved quality variable $q$. As discussed e.g. in Wooldridge (2012), p. 67, a genuine proxy variable must be redundant in the underlying structural relationship if the unobserved variable for which it fills in were actually included in the model. We specifically abstract from such a case by allowing trees to affect home values even in absence of MPB damage.
} 
Thus, the reduced-form parameter $\beta(q)=\frac{\partial P(.)}{\partial f(.)}\left(\theta_{1}-\theta_{2}\right) \alpha^{\prime}(q)$ captures the combined effect of tree preferences and MPB damage. It can be directly interpreted as the per-tree (or unit of biomass) implicit price of $q$. The key question now becomes under which conditions we can relate the coefficient on $h$ in an empirical price function to $\beta(q)$, and thus to the implicit price of the unobserved environmental quality. This constitutes the methodological crux of the TAM. Taking the derivative of $P($.$) with respect to h$ yields

$$
\frac{\partial P(.)}{\partial h}=\frac{\partial P(.)}{\partial f(.)}\left(\theta_{1}-\theta_{2}\right) \alpha(q)+\theta_{2}
$$

Thus, in a basic cross-sectional data set of home sales we can only identify $\beta(q)$ from (7) if $\alpha^{\prime}(q)=\alpha(q)$ and if, in addition $\theta_{2}=0$. The first condition places strong restrictions on the damage function, and the second - the absence of any appreciation effects for $h$-is unlikely to hold in most settings, as discussed above.

This dilemma can be overcome if we interpret the implicit price of $q$ as a (small) change in its level over time, and if we cast our analysis in a Repeat Sales (RS) framework. Thus, we let $\alpha^{\prime}(q) \approx \alpha\left(q_{t}\right)-\alpha\left(q_{t-1}\right)$, for two sales of the same property observed at times $t$ and $t-1$.

This changes (6) to:

$$
\frac{\partial P(.)}{\partial q}=\frac{\partial P(.)}{\partial f(.)} \frac{\partial f(.)}{\partial q} \approx \frac{\partial P(.)}{\partial f(.)}\left(\theta_{1}-\theta_{2}\right)\left(\alpha\left(q_{t}\right)-\alpha\left(q_{t-1}\right)\right) h \approx \beta(q) h
$$

Now consider an RS model where instead of the derivative of price with respect to $q$ we focus on price differences over time due to a change in $q$. For example, for the widely used exponential specification of the price function we have, at time $t$,

$$
\begin{aligned}
P\left(f\left(h, q_{t}, \boldsymbol{\theta}\right), \mathbf{x} ; \boldsymbol{\delta}\right) & =\exp \{f(.)\} \exp (\mathbf{x} ; \boldsymbol{\delta}) \\
& =\exp \left\{\theta_{1} \alpha\left(q_{t}\right) h+\theta_{2}\left(1-\alpha\left(q_{t}\right)\right) h\right\} \exp (\mathbf{x} ; \boldsymbol{\delta})
\end{aligned}
$$

The differential between logged sales prices at times $t$ and $t-1$ can then be written as 4

$$
\begin{aligned}
\ln \left(P_{t}\right)-\ln \left(P_{t-1}\right) & =\left(\theta_{1}-\theta_{2}\right)\left[\alpha\left(q_{t}\right)-\alpha\left(q_{t-1}\right)\right] h+\theta_{2} h-\theta_{2} h \\
& =\left(\theta_{1}-\theta_{2}\right)\left[\alpha\left(q_{t}\right)-\alpha\left(q_{t-1}\right)\right] h \approx(1 / P) \beta(q) h,
\end{aligned}
$$

where the last term in the second line follows from $\frac{\partial P(.)}{\partial f(.)}=P$ for this model. Thus, for small changes of $q$ over time the coefficient of $h$ in a standard differenced hedonic price function directly approximates the implicit price of $q$ per unit of $h$, expressed as usual in terms of a proportional change in price. ${ }^{5}$

Naturally, for larger changes in $q$ between the two time periods this interpretation of "marginal welfare effect" becomes tenuous. However, the coefficient on $h$ can still be unambiguously interpreted as the capitalization effect of $q$ on home prices. This holds because the pure "appreciation effect" $\theta_{2} h$ cancels out in the differenced price function, as shown explicitly in (10).

The importance of an RS approach to assure a utility-theoretic foundation for TAs raises concerns as to their interpretation in cross-sectional applications. This may explain the mixed signals in Kovacs et al's (2011) cross-sectional version of their model for the presence of oak

\footnotetext{
4 We assume for now that all other components in the price function difference out.

5 For the less common linear price function with additive attributes we have $\frac{\partial P(.)}{\partial f(.)}=1$, and would thus obtain $P_{t}-P_{t-1}=\left(\theta_{1}-\theta_{2}\right)\left[\alpha\left(q_{t}\right)-\alpha\left(q_{t-1}\right)\right] h \approx \beta(q) h$. That is, the coefficient on $h$ would directly approximate the implicit price of $q$.
} 
woods within different perimeters and log-distances of a given residence. The coefficients for these terms likely capture both the amenity value of healthy oaks and the detrimental effect of diseased trees. Thus, they cannot be interpreted as the marginal WTP of the typical resident to curb the spread of southern oak death. Similarly, the estimated coefficients on distance to impaired river segments, which all lack statistical significance, in Cho et al. (2011) likely muddle the pollution effect from the paper mill with potentially beneficial attributes of even a polluted waterway, such as cooling effects during summer. Conversely, Kovacs et al's (2011) RS version of their hedonic model produces substantially more significant and intuitively sound results than their cross-sectional specification, with the effect of nearby oak woods turning increasingly more negative over time.

In practical hedonic modeling both $h$ and $q$ will likely be property-specific. The latter implies a unique marginal effect of $\beta_{i}=\beta\left(q_{i}\right)$ for residence $i$. The identification of these heterogeneous effects requires a panel of differenced home sales for each individual property. If this is not available $q_{i}$ needs to be assumed constant for clusters of homes. Thus, a certain degree of aggregation may still be required to render the TAM operational. While this erodes the TAM's potential advantage over the aggregate exposure approach discussed above to some degree, the aggregation over homes with a stipulated common $q$ can likely be accomplished at a much more refined level than the broad "noise zones" or "pollution contours" generally employed in the former strand of literature, since only a few observations are required to identify $\beta\left(q_{i}\right)$ for a given level of $q_{i}$. In our application we normalize $h$ to one, de facto separating the sample into homes with $\left(h_{i}=1\right)$ and without $\left(h_{i}=0\right)$ host trees within a specific perimeter. This reduces $\beta_{i}$ to a single marginal effect (specific to a given perimeter) that can be interpreted as the MPB effect for the typical property near host trees.

\section{Econometric Model}

Let the logged sales price of home $i$, located in market area $s$, at time $t$ be given as

$$
\begin{aligned}
& \ln P_{i s t}=\alpha_{s t}+g\left(\mathbf{x}_{i s}, \boldsymbol{\delta}_{i s}\right)+\mathbf{h}_{i}^{\prime} \mathbf{f}(.)+\mathbf{w}_{i t}^{\prime} \boldsymbol{\psi}+\epsilon_{i s, t} \text { with } \\
& \epsilon_{i s, t} \sim n\left(0, \sigma^{2}\right), \quad i=1 \ldots N, \quad t=1 \ldots T, \quad s=1 \ldots S .
\end{aligned}
$$

The intercept term $\alpha_{s t}$ captures both the area-specific housing market price trend, and any other area and time-varying unobservables that affect sales price. As discussed in Dastrup et al. (2012) in the context of solar panel installations, allowing for area-specific market appreciation is important when geography-specific price patterns may be correlated with local dynamics of environmental conditions.

In our case, a legitimate concern is that the MBP infestation rate observed for our time frame correlates with rapidly rising fuel prices. The latter will increase daily transportation and climate control costs for the typical household asymmetrically across neighborhoods, depending on local climate, commuting patterns, and local commercial infrastructure. Specifically, more remote areas at higher elevations and with longer daily commutes to employment centers will be relatively more affected by rising fuel costs than homes in lower elevations and near urban centers. These increased fuel costs are likely capitalized into home values, leading to more pronounced losses in home values in these remote locations over time. However, the exact same neighborhoods are also more likely located in the MPB host tree zone. Thus, the MPB effect on home values would be confounded with the effect of rising fuel costs if we forced the same market price trend over the entire region. This is clearly confirmed by our estimation results. 
Function $g$ (.) in Eq. (11) combines time-invariant home and neighborhood characteristics $\mathbf{x}_{i s}$ with preference parameters $\boldsymbol{\delta}_{i s}$. Conveniently, the exact form and contents of $g$ (.) need not be known, as this term will drop out of the estimable equation after differencing. This is the main advantage of the repeat sales model over a traditional hedonic approach, as discussed in numerous existing contributions (e.g. Palmquist 1982; Mendelsohn et al. 1992; Carbone et al. 2006). ${ }^{6}$

The remaining two observed characteristics, $\mathbf{h}_{i}$ and $\mathbf{w}_{i t}$ are associated with time-varying environmental conditions, and thus need to be explicitly included in our model. As discussed above, $\mathbf{h}_{i}$ is a metric for host trees near a given residence. Specifically, since the MPB effect may vary over distance from the actual lot, we let $\mathbf{h}_{i}$ be a vector of host tree indicators associated with different perimeters surrounding a given property. The corresponding vector f (.) contains a set of translating functions as defined in (5), one for each perimeter.

Analogously, vector $\mathbf{w}_{i t}$ includes a set of $0 / 1$ terms indicating if a wildfire occurred within discrete distance zones of the home, and within a discrete set of years preceding the sales date. Controlling for such fire effects is important as wildfire occurrences are, not surprisingly, spatially correlated with the presence of MPB host trees, and-at least to some extenttemporally correlated with the MPB infestation trajectory. Similar to the case of spatially and temporally varying energy costs, this could lead to erroneous estimates of the MPB effect if left ignored. Note that the corresponding coefficient vector, $\psi$, is modeled as timeand space invariant. This requires the assumption that the impact of nearby wildfires on sales prices, after controlling for distance and time lag, remains constant throughout the entire region and time window. This appears reasonable in our case as the "post-fire" look of a scorched landscape should be similar over time and space.

Our period-specific model is completed with the inclusion of a standard idiosyncratic, normally distributed error term, as shown in (11). Now suppose a given property sells at two points in time, $t^{\prime}$ and $t^{0}$, with $t^{\prime}$ denoting the more recent sale. Specifying (11) for both periods and differencing yields our Repeat Sales Model (RSM), which can be compactly written as

$$
\begin{aligned}
y_{i s,\left(t^{\prime}, t^{0}\right)}= & \ln \left(\frac{P_{i s, t^{\prime}}}{P_{i s, t^{0}}}\right)=\ln P_{i s, t^{\prime}}-\ln P_{i s, t^{0}} \\
= & \sum_{s=1}^{S} \xi_{s}+\mathbf{h}_{i}^{\prime} \zeta+\sum_{t=2}^{T}\left(\alpha_{s t} * d_{t}\right)+\mathbf{h}_{i}^{\prime} \sum_{t=2}^{T}\left(\boldsymbol{\beta}_{t} * d_{t}\right) \\
& +\left(\mathbf{w}_{i t^{\prime}}^{\prime}-\mathbf{w}_{i t^{0}}^{\prime}\right) \psi+\sum_{s=1}^{S}\left(\delta_{s} a_{i,\left(t^{\prime}, t^{0}\right)}\right)+e_{i s,\left(t^{\prime}, t^{0}\right)}
\end{aligned}
$$

where $d_{t}$ is a tri-valued indicator equal to 1 if $t=t^{\prime},-1$ if $t=t^{0}$, and 0 otherwise, and $e$ (.) is the differenced error term with mean zero and variance of $2 \sigma^{2}{ }^{7}$ For identification purposes, the first time period in the empirical series, i.e. $t=1$, is chosen as a baseline with implicit price index of 1 . This allows for $T-1$ time-specific appreciation coefficients for each area $s$, as well as $T-1$ time-specific coefficient vectors $\boldsymbol{\beta}_{t}$ for the host tree variable $\mathbf{h}_{i}$.

\footnotetext{
6 Naturally, the assumption of time-invariance of both characteristics and preferences is crucial for this advantage to be properly exploited. Since the time periods for our analysis are relatively short (9-12 years) we do not expect pronounced shifts in underlying preferences in our data. In addition, we control for changes in home structures by eliminating properties with documented home improvements from our sample, as discussed in the empirical section.

7 For further details and motivation for this tri-valued indicator approach see, for example, Palmquist (1982) and Case et al. (2006).
} 
As discussed in the preceding section the elements of $\boldsymbol{\beta}_{t}$ can be directly interpreted as the perimeter-specific effect of MPB damage on home values.

Our empirical model is completed by adding three additional components: (i) timeinvariant area indicators $\xi_{s}$, (ii) time-invariant host-tree effects $\mathbf{h}_{i}^{\prime} \zeta$, and (iii) area-specific

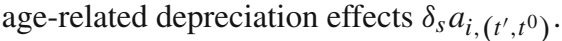

As discussed in Goetzmann and Spiegel (1995) and Case et al. (2006) the time-invariant area indicators $\xi_{s}$ capture any nontemporal components of house price appreciation, e.g. via last-minute refurbishing or minor physical improvements prior to a sale. As illustrated in Mendelsohn et al. (1992) these terms can be structurally motivated by adding the " $t$ th time-of-sale" to Eq. (11), such that the difference produces a simple unitary index.

Similarly, the time-invariant host tree effects capture the differential nontemporal price effect between homes in the host tree zone and homes without host trees. For example, it is possible that homes "in the woods" exert more pre-sale cleanup efforts than homes in open environments. Alternatively, and perhaps more intuitively from an econometric perspective, $\zeta$ can be interpreted as the average differential price effect between homes with host trees and homes without in the baseline time period. The inclusion of this effect turns out to be of critical importance in our empirical application. ${ }^{8}$

Finally, the age-depreciation effect is designed to capture additional home-specific price changes based solely on structural deterioration due to the amount of time that has passed between a pair of temporally adjacent sales. It is a well known "nuisance" in RSMs that age-depreciation cannot enter the model linearly due perfect collinearity with the temporal indicators $d_{t}$ (e.g. Palmquist 1980; Chau et al. 2005; Francke 2010). We follow Francke (2010) in spirit and let age depreciation be nonlinearly related to a home's age at the current and preceding sale, i.e.

$$
a_{i,\left(t^{\prime}, t^{0}\right)}=\ln \left(\frac{A_{t^{\prime}}-A_{t^{0}}}{A_{t^{0}}}\right)
$$

where $A$ denotes age in years since construction. This allows for the interpretation of the corresponding coefficient $\delta_{s}$ as the percentage effect on price change of a one percent change in time passed between sales relative to baseline age.

The model in (12) is fit for estimation with one additional econometric adjustment. If a property sells $\tau$ times during our research period, it will contribute $\tau-1$ observations to the repeat sales data. As discussed in Palmquist (1982) and Case et al. (2006), if $\tau>2$ this introduces a non-zero, but known error correlation for such properties. This can be accommodated in straightforward fashion via Generalized Least Squares (GLS) procedures.

\section{Empirical Application}

\subsection{Rationale for a Translating Commodity—Approach}

The Mountain Pine Beetle (MPB, dentroctonus ponderosae) is a forest pest native to North America. In recent years, its population growth has taken landscape-level proportions. According to scientists, this is likely related to milder winter climates, but may also be facilitated by the monoculture stands of pines of homogeneous age that have resulted from decades of selective forestry (Carroll et al. 2004; Bentz et al. 2010; Sims et al. 2010). In recent years between 6 and 10 million acres of forest have been lost annually to MPB infestation

${ }^{8}$ Conceptually, both $\xi$ and $\zeta$ can be interpreted as elements of the reduced form parameter vector $\delta$ in our theoretical model [Eq. (1)]. 
in the western United States alone (Man 2012). These figures are essentially at par with the annual, country-wide damage inflicted by wildfires. ${ }^{9}$ In the Colorado Front Range, infestations were spotty and beyond the Wildland-Urban-Interface (WUI) until the mid-2000s, but have grown exponentially and penetrated into the WUI in the last 5-7 years.

An infected pine tree dies within a few weeks. Its needles turn red within a year, and gray within three to four years. Ideally, MPB density would be measured as beetles per tree section or spacial unit. However, such detailed metrics are not available on the regional scale needed for our analysis. This makes a shift of focus to the translating commodity "host trees" attractive.

If the percentage of damaged trees or biomass, i.e. the term $\alpha(q)$ in our structural model were known, we could in theory estimate separate implicit prices for injured and healthy trees. This would be similar in spirit to Holmes et al. (2006) and Holmes et al. (2010), who, using satellite image differencing techniques, assign each image pixel of their study area to one of five damage classes of hemlock trees afflicted by the Hemlock Woolly Adelgid (HWA). They then derive the percentage of area occupied by a given damage class within a specific perimeter of an individual residence, and estimate the marginal effect on home values of a $1 \%$ increase for each damage class in a cross-sectional hedonic regression model.

Such refined satellite image processing was not available and/or feasible for our entire research area and time frame. An alternative measure of beetle damage based on the US Forest Service's annual Areal Detection Surveys (ADSs) proved too imprecise to yield meaningful results. ${ }^{10}$ We thus settle for a feasible alternative strategy based on host tree data alone without explicit distinction between healthy and infested trees. As described above, this information suffices to identify MPB impacts on home values, if an RS approach is taken for estimation. We assign a binary indicator to each property and perimeter, based on the presence (" 1 ") or absence ("0") of MPB host trees. We then estimate separate coefficients for this indicator for each year of our research period. The change over time of these coefficients can then be used to derive annual marginal losses of home values due to the progressing infestation.

This approach is conceptually equivalent to that taken by Kovacs et al. (2011) in the context of Sudden Oak Death (phytophtora ramorum). They assign properties to different categories based on their distance to the nearest stand of host trees (live oak woodlands), and use these indicators in a variety of hedonic regression models, including an RS specification.

9 In 2006, 2007, and 2012, the three worst wildfire seasons in history, wildfires consumed over 9 million acres in the US (National Interagency Fire Center 2012).

10 A full-fledged damage analysis via satellite imagery and visual damage coding by a remote sensing expert for all included properties in our data would have been infeasible given resource constraints and our relatively large sample size. In addition, high-quality satellite images covering our entire research area are only available for a select few years of our research period, which would hamper a seamless analysis of the MPB damage trajectory over time. The ADS, in turn, uses fly-overs and hand-drawn polygons to identify infested areas. Each polygon, in turn, receives an estimate for the total number of infested trees within its boundary. Price et al. (2010) use these polygons for their study of MPB damage and property values in neighboring Grant County to compute the expected number of diseased trees within different perimeters of each residence. Using a cross-sectional regression model with spatial lags they estimate the marginal implicit price per tree for each perimeter. They also report that the accuracy of this polygon-based damage information ranges between 61 and $79 \%$, based on a 2005 FS assessment. However, MPB damage was more confined and localized in the mid-90s to mid-2010s (the time span of their analysis), generally allowing for tighter, stand-specific polygons. This accuracy has suffered in recent years, as polygons had to be drawn at ever larger scales to keep pace with the dramatic acceleration and expansion of the infestation. For our time frame, which reaches to 2011, a polygon-based estimation approach did not produce reliable results. Too many homes are included within the same large-scale polygon, and thus receive identical damage metrics in the last four to five years of our research period. In addition, a comparison with satellite images for sub-areas and years for which they are available revealed a high degree of imprecision between polygon boundaries and actual damage. The results of the polygon-based version of our model are available upon request. 
However, in contrast to our application, they do not allow for area-specific basic price trends, age-related depreciation, or error correlation for properties with multiple repeat sales. We found all three components to have a significant influence on estimation results for our data.

\subsection{Data}

\subsubsection{Home Sales Data}

The data on home sales were purchased from DataQuick, a private vendor which consolidates real estate data from county assessor's offices around the country. Our set comprises all singlefamily homes that were assessed in 2011, constituting de facto the entire single-family housing stock for each county. This yields a starting point of 90,993 properties for Larimer County and 81,835 residences for Boulder County. For Larimer, data with documented sale transactions are available starting in 1998. For Boulder, the starting year is 2002.

From this initial set we eliminate homes without an observed sale, and all secondary residences. We also drop any transactions that were flagged as not being at arm's-length, or that correspond to homes with documented major improvements between sales, or homes that sold twice within the same calendar year ("flip-sales"). This yields a retained sample of 40,981 homes for Larimer and 24,846 residences for Boulder, for a combined number of 141,106 observed sales transactions. This sample further reduces to 29,543 observations (21,684 for Larimer, 7,859 for Boulder) on sales that can be paired with one or more preceding sale for the same property. This corresponds to a total of 23,151 homes (16,427 for Larimer, 6,724 for Boulder) in our final RSM sample. ${ }^{11}$

Each retained residence was geo-coded using state-of-the-art precision software. ${ }^{12}$ For reasons discussed in the preceding section, we further assign each home to one of seven "markets", based on geographic considerations and expected differences in general home price trajectories. Specifically, we divide Larimer into five markets (henceforth referred to as areas one through five), while Boulder is split into two markets (henceforth labeled as areas six and seven).

Figure 1 provides an overview of the research area. It depicts the seven sub-markets ("areas") and the location of included properties. Darkened dots indicate properties that have host trees withing a perimeter of 0.1 kilometers $(\mathrm{km})$. Areas one ("North Larimer Mountains"), four ("South Larimer Mountains") and six ("Boulder Mountains") are located in the foothills and higher elevations of the Colorado Rockies, whereas the remaining areas occupy primarily the plains bordering the Front Range. Specifically, area three ("Central Ft. Collins") encompasses central Fort Collins, while area two includes its suburbs to the north ("North Ft. Collins"). Area five ("South Ft. Collins") comprises Ft. Collins' southern expansions, plus the city of Loveland with its satellite communities Berthoud and Johnstown. Area seven ("Boulder City") in Boulder County includes the city of Boulder near its western boundary, the city of Longmont in its north-eastern corner, and the communities of Superior, Louisville, and Lafayette near its south-eastern perimeter.

\footnotetext{
11 A comparison of the repeat-sales sample with the general sample (including single-transaction residences) based on basic home features did not reveal any systematic differences between the two groups. We thus conclude that repeat-sales properties do not constitute a systematically different segment of the housing market.

12 Specifically, we used release 2 of the ESRI StreetMap Premium/NAVTEQ USA software package to geocode each property. A majority of geocodes provided by this package (greater than $88 \%$ for both counties) are based on exact property centroids, as opposed to uniformly assigned street segments.
} 


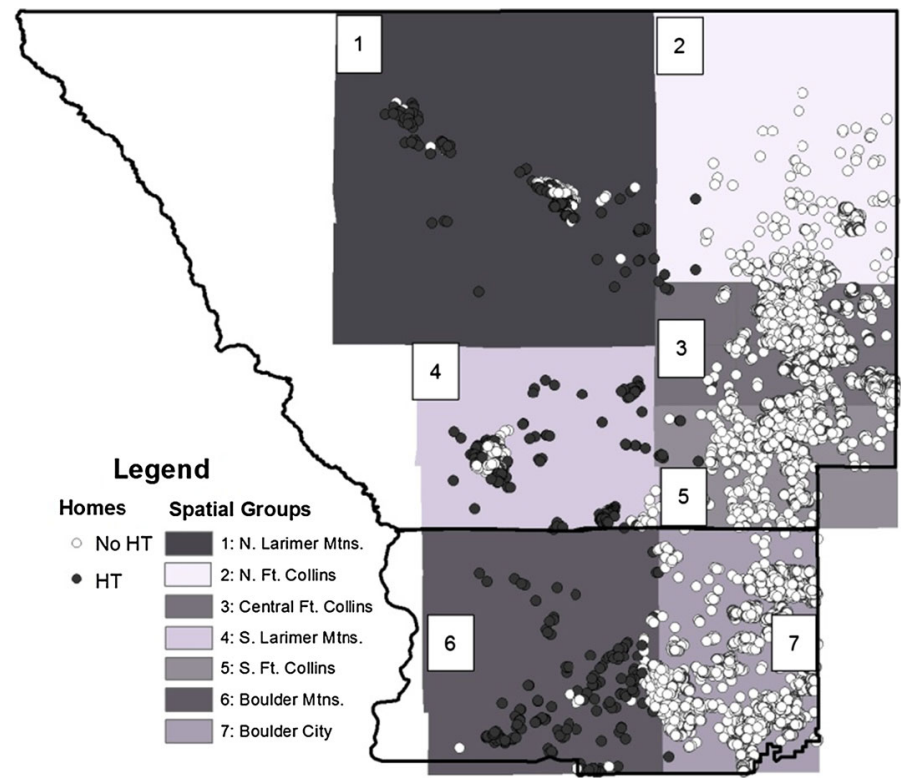

Fig. 1 Overview of research area

Table 1 Property counts by area and host tree zone

\begin{tabular}{|c|c|c|c|c|c|c|c|c|}
\hline \multirow[t]{2}{*}{ Area } & \multicolumn{4}{|l|}{ HT zone } & \multicolumn{4}{|c|}{ HT zone } \\
\hline & None & $0.1 \mathrm{~km}$ & $1 \mathrm{~km}$ & All & None & $0.1 \mathrm{~km}$ & $1 \mathrm{~km}$ & All \\
\hline & Larimer & & & & Boulde & & & \\
\hline 1 & 2 & 169 & 257 & 259 & - & - & - & - \\
\hline 2 & 2,571 & 2 & 32 & 2,603 & - & - & - & - \\
\hline 3 & 12,987 & 3 & 49 & 13,036 & - & - & - & - \\
\hline 4 & 6 & 317 & 452 & 458 & - & - & - & - \\
\hline 5 & 5,299 & 5 & 29 & 5,328 & - & - & - & - \\
\hline 6 & - & - & - & - & 150 & 209 & 378 & 528 \\
\hline 7 & - & - & - & - & 7,197 & 4 & 134 & 7,331 \\
\hline All & 20,865 & 496 & 819 & 21,684 & 7,347 & 213 & 512 & 7,859 \\
\hline
\end{tabular}

$\mathrm{HT}=$ host trees; $1 \mathrm{~km}$ zone nests $0.1 \mathrm{~km}$ zone

The mountainous areas one, four, and six comprise primarily smaller settlements along the main highway routes. The sole exception is the town of Estes Park, located near the center of area four in Larimer County. Estes Park is widely considered the "eastern gateway to Rocky Mountains National Park". It offers a mixed housing stock for permanent residents, interspersed with vacation homes, rental cabins, and other tourism-driven infrastructure.

Table 1 shows the number of observations in our data set for each area, differentiated by the presence or absence of host trees within two perimeters: 0.1 and $1 \mathrm{~km}$, where the wider perimeter nests the smaller one. As is evident from both Fig. 1 and Table 1, our identification of the MPB effect via host trees, which is ultimately based on the $0.1 \mathrm{~km}$ delineation, will primarily flow from the mountainous areas one, four, and six. However, the remaining areas 
Table 2 Property counts by year and host tree zone

\begin{tabular}{|c|c|c|c|c|c|c|c|c|}
\hline \multirow[t]{2}{*}{ Year } & \multicolumn{4}{|l|}{ HT zone } & \multicolumn{4}{|c|}{ HT zone } \\
\hline & None & $0.1 \mathrm{~km}$ & $1 \mathrm{~km}$ & all & None & $0.1 \mathrm{~km}$ & $1 \mathrm{~km}$ & All \\
\hline & Larimer & & & & Boulder & & & \\
\hline 1999 & 207 & 8 & 11 & 218 & - & - & - & - \\
\hline 2000 & 545 & 19 & 30 & 575 & - & - & - & - \\
\hline 2001 & 873 & 17 & 33 & 906 & - & - & - & - \\
\hline 2002 & 1,176 & 25 & 49 & 1,225 & - & - & - & - \\
\hline 2003 & 1,431 & 37 & 63 & 1,494 & 57 & 1 & 5 & 62 \\
\hline 2004 & 1,797 & 38 & 72 & 1,869 & 283 & 8 & 21 & 304 \\
\hline 2005 & 2,096 & 54 & 86 & 2,182 & 608 & 21 & 40 & 648 \\
\hline 2006 & 2,102 & 68 & 104 & 2,206 & 882 & 21 & 58 & 940 \\
\hline 2007 & 2,518 & 66 & 105 & 2,623 & 1,208 & 35 & 75 & 1,283 \\
\hline 2008 & 2,160 & 45 & 72 & 2,232 & 1,156 & 19 & 70 & 1,226 \\
\hline 2009 & 2,095 & 37 & 64 & 2,159 & 1,070 & 28 & 64 & 1,134 \\
\hline 2010 & 2,134 & 47 & 70 & 2,204 & 1,120 & 41 & 87 & 1,207 \\
\hline 2011 & 1,731 & 35 & 60 & 1,791 & 963 & 39 & 92 & 1,055 \\
\hline All & 20,865 & 496 & 819 & 21,684 & 7,347 & 213 & 512 & 7,859 \\
\hline
\end{tabular}

$\mathrm{HT}=$ host trees; $1 \mathrm{~km}$ zone nests $0.1 \mathrm{~km}$ zone

still provide important information for the identification of fire effects, which are assumed to be homogeneous across the region.

Table 2 lists the number of observations by year across the entire region and by host tree proximity. Naturally, annual counts increase for the first few years in our series as more and more properties enter the data. After this initial "recruitment" period, sale counts stabilize at approximately 2,000-2,500 per year in Larimer, and 1,000-1,200 per year for Boulder. In both counties, sale counts peak in 2007-the onset of the recession. After that, sales gradually drop to under 1,800 (Larimer) and under 1,000 (Boulder) by 2011, the last year of our research period. Sales with host trees (HTs) in the immediate $(0.1 \mathrm{~km})$ and general $(1 \mathrm{~km})$ vicinity generally follow this pattern for both counties.

Annual statistics on sales price (in 2011 dollars, units of 000s) are given in Table 3. As is evident from the table, homes in Boulder County generally sold for approximately 45-60\% more than properties in Larimer. For the latter county, the average observed price generally increases until 2006, after which it generally declines during the recession years. By 2011, the average sales price is comparable to the "pre-bubble" level of 2000. For Boulder, our series starts with a clear peak in 2003, which is followed by a rapid and rather pronounced decline, dropping to approximately $80 \%$ of 2003 values in the last three years of our time window. Tables 10 and 11 in "Appendix 1" provide annual price statistics for each sub-market.

As can be seen from Table 4, the difference in home values between the two counties is at least partially related to differences in basic home features. Specifically, residences in Boulder are generally larger and have more bedrooms and bathrooms than those in Larimer, although this difference is negligible for areas seven (cities of Boulder, Longmont) versus three (central Fort Collins). In contrast, properties in mountainous Boulder (area six) clearly dominate their counterparts in mountainous Larimer (areas four and six) on all three accounts. 
Table 3 Price statistics by year (2011 dollars)

\begin{tabular}{|c|c|c|c|c|c|c|c|c|}
\hline \multirow[t]{2}{*}{ Year } & \multicolumn{4}{|c|}{ Larimer $(\$ 000 \mathrm{~s})$} & \multicolumn{4}{|c|}{ Boulder (\$000s) } \\
\hline & Mean & SD & Min & Max & Mean & SD & Min & Max \\
\hline 1999 & 239 & 86 & 80 & 695 & - & - & - & - \\
\hline 2000 & 254 & 107 & 59 & 1,094 & - & - & - & - \\
\hline 2001 & 270 & 94 & 76 & 889 & - & - & - & - \\
\hline 2002 & 274 & 105 & 58 & 1,453 & - & - & - & - \\
\hline 2003 & 284 & 111 & 31 & 1,281 & 465 & 230 & 193 & 1,464 \\
\hline 2004 & 277 & 107 & 90 & 1,172 & 428 & 262 & 119 & 2,797 \\
\hline 2005 & 280 & 112 & 39 & 1,333 & 431 & 245 & 126 & 3,278 \\
\hline 2006 & 286 & 127 & 74 & 1,400 & 425 & 255 & 106 & 2,296 \\
\hline 2007 & 270 & 124 & 38 & 1,642 & 407 & 276 & 82 & 3,078 \\
\hline 2008 & 258 & 127 & 64 & 1,664 & 377 & 236 & 73 & 2,293 \\
\hline 2009 & 251 & 109 & 72 & 1,155 & 365 & 217 & 82 & 3,045 \\
\hline 2010 & 260 & 119 & 57 & 1,298 & 380 & 231 & 69 & 2,189 \\
\hline 2011 & 252 & 109 & 67 & 920 & 393 & 266 & 75 & 2,600 \\
\hline
\end{tabular}

$S D$ standard deviation; $\min (\max )$ minimum (maximum)

\subsubsection{Host Tree and Fire Data}

GIS data on the spatial distribution of host trees were compiled by the FS's Forest Inventory and Analysis Program and the Remote Sensing Applications Center. They are available to the public via the Forest Service's Geodata Clearinghouse (USDA Forest Service 2012a). The data layers are based on 2002-2003 Moderate Resolution Imaging Spectroradiometer (MODIS) satellite images of 28 forest type groups across the contiguous US, plus nearly 100 other geospatial layers. These data are published at a pixel size of $250 \mathrm{~m}$. Each pixel, in turn, carries an assessed probability of $66 \%$ of correctly identifying forest communities (Ruefenacht et al. 2008). From this dataset we extracted the locations of pine species that are known to be hosts for MPB. ${ }^{13}$

As discussed above, the FS's areal survey data on MPB damage proved too coarse for direct incorporation in our RS model. However, it can still provide meaningful information on aggregate damage and its progression over time. Table 5 shows tree mortality statistics over time, aggregated over all 0.1 and $1 \mathrm{~km}$ perimeters, respectively, surrounding all homes in our data that are located near HTs. For example, the typical home in either county's HT zone had virtually no infested tree within $0.1 \mathrm{~km}$ and at most a handful of impacted trees within $1 \mathrm{~km}$ up until 2007. In stark contrast, damage counts exhibit explosive behavior for the last

\footnotetext{
13 Specifically, our GIS layer includes the following groups of pine species: White/Red/Jack, Lodgepole, Longleaf/Slash, Loblolly/Shortleaf, Pinyon/Juniper, Ponderosa, and Western White. Of these, the relevant species for Colorado are Lodgepole, Ponderosa, and Limber (a member of the Western White group). All of them are equally susceptible to an MPB attack (personal communication with Dr. Barbara Bentz, research entomologist at the US Forest Service. Logan, Utah). Since our host tree indicator $h_{i}$ is also indiscriminant over these species, the accuracy rating for correctly identifying any host tree community likely exceeds that for specific pine types.
} 
Table 4 Home features by area

\begin{tabular}{|c|c|c|c|c|c|c|c|c|}
\hline \multirow[t]{2}{*}{ Feature } & \multicolumn{4}{|c|}{ Larimer $(\$ 000 \mathrm{~s})$} & \multicolumn{4}{|c|}{ Boulder $(\$ 000 s)$} \\
\hline & Mean & SD & Min & Max & Mean & SD & Min & $\operatorname{Max}$ \\
\hline & Area 1 & & & & Area 6 & & & \\
\hline Bathrms. & 1.64 & 0.79 & 0 & 4 & 2.92 & 1.19 & 1 & 7 \\
\hline Bedrms. & 2.64 & 0.87 & 0 & 5 & 3.28 & 0.94 & 1 & 6 \\
\hline \multirow[t]{2}{*}{ Sqft (000) } & 1.53 & 0.57 & 0.32 & 3.87 & 1.95 & 0.80 & 0.48 & 5.74 \\
\hline & Area 2 & & & & Area 7 & & & \\
\hline Bathrms. & 1.90 & 0.80 & 1 & 10 & 2.79 & 1.04 & 0 & 9 \\
\hline Bedrms. & 3.19 & 0.77 & 1 & 6 & 3.44 & 0.91 & 0 & 7 \\
\hline \multirow[t]{2}{*}{ Sqft (000) } & 1.56 & 0.59 & 0.53 & 6.44 & 1.77 & 0.76 & 0.55 & 8.32 \\
\hline & Area 3 & & & & & & & \\
\hline Bathrms. & 2.30 & 0.83 & 1 & 8 & & & & \\
\hline Bedrms. & 3.44 & 0.87 & 0 & 9 & & & & \\
\hline \multirow[t]{2}{*}{ Sqft (000) } & 1.79 & 0.59 & 0.45 & 5.38 & & & & \\
\hline & Area 4 & & & & & & & \\
\hline Bathrms. & 1.97 & 0.89 & 0 & 7 & & & & \\
\hline Bedrms. & 2.95 & 0.94 & 1 & 7 & & & & \\
\hline \multirow[t]{2}{*}{ Sqft (000) } & 1.59 & 0.62 & 0.48 & 5.45 & & & & \\
\hline & Area 5 & & & & & & & \\
\hline Bathrms. & 2.02 & 0.79 & 1 & 6 & & & & \\
\hline Bedrms. & 3.22 & 0.87 & 0 & 7 & & & & \\
\hline \multirow[t]{2}{*}{ Sqft (000) } & 1.61 & 0.55 & 0.43 & 4.69 & & & & \\
\hline & All & & & & All & & & \\
\hline Bathrms. & 2.17 & 0.84 & 0 & 10 & 2.80 & 1.05 & 0 & 9 \\
\hline Bedrms. & 3.33 & 0.87 & 0 & 9 & 3.43 & 0.91 & 0 & 7 \\
\hline Sqft (000) & 1.71 & 0.59 & 0.32 & 6.44 & 1.78 & 0.77 & 0.48 & 8.32 \\
\hline
\end{tabular}

$S D$ standard deviation; $\min (\max )$ minimum (maximum)

bathrms bathrooms, bedrms. bedrooms, sqft square footage

four years of our series, amounting to close to 20 trees within $0.1 \mathrm{~km}$ and over 2,000 trees within $1 \mathrm{~km}$ for Larimer County. This accelerating pattern is the same for Boulder, though absolute damage counts remain somewhat lower than in Larimer.

A visual interpretation of this trend is given in Fig. 2, which depicts our included re-sale properties (clusters of gray dots), and the FS's ADS polygons for 1997, 2000, 2007, and 2011. As is evident from the figure, MPB damage was spotty with island-like concentrations in 1997 and 2000. By 2007, the infestation had already progressed to cover most of the mountain chain along the eastern border of both counties, albeit with limited overlap with the WUI. This changes dramatically by 2011, which depicts ample and widespread overlap of MPB activity with human-built environments.

Our data set is completed by adding annual wildfire information using FS Monitoring Trends in Burn Severity (MTBS) and Wildland Fire Decision System Support (WFDSS) shape files (Eidenshink et al. 2007; USDA Forest Service 2012b, c). As shown in Stetler et al. (2010) fires up to seven years prior to a home sale and up to $10 \mathrm{~km}$ from a 
Table 5 Tree mortality by year

\begin{tabular}{|c|c|c|c|c|c|c|c|}
\hline \multirow[t]{2}{*}{ Table 5} & \multirow[t]{2}{*}{ Year } & \multicolumn{3}{|c|}{ Larimer $(n=620)$} & \multicolumn{3}{|c|}{ Boulder $(n=440)$} \\
\hline & & Mean & SD & $\operatorname{Max}$ & Mean & SD & $\operatorname{Max}$ \\
\hline & \multicolumn{7}{|c|}{ Within $0.1 \mathrm{~km}$} \\
\hline & 1997 & 0.03 & 0.44 & 8 & 0.00 & 0.02 & 0 \\
\hline & 1998 & 0.02 & 0.20 & 3 & 0.07 & 0.55 & 8 \\
\hline & 1999 & 0.01 & 0.08 & 2 & 0.05 & 0.27 & 3 \\
\hline & 2000 & 0.03 & 0.40 & 7 & 0.01 & 0.22 & 5 \\
\hline & 2001 & 0.05 & 0.52 & 8 & 0.04 & 0.47 & 6 \\
\hline & 2002 & 0.03 & 0.31 & 5 & 0.00 & 0.03 & 1 \\
\hline & 2003 & 0.01 & 0.07 & 1 & 0.01 & 0.20 & 4 \\
\hline & 2004 & 0.01 & 0.07 & 1 & 0.00 & 0.05 & 1 \\
\hline & 2005 & 0.01 & 0.14 & 2 & 0.00 & 0.04 & 1 \\
\hline & 2006 & 0.00 & 0.04 & 1 & 0.00 & 0.00 & 0 \\
\hline & 2007 & 0.00 & 0.05 & 1 & 0.03 & 0.24 & 4 \\
\hline & 2008 & 0.26 & 3.87 & 66 & 0.52 & 4.27 & 51 \\
\hline & 2009 & 0.99 & 5.10 & 78 & 1.11 & 5.89 & 39 \\
\hline & 2010 & 5.53 & 14.06 & 78 & 1.92 & 7.50 & 76 \\
\hline & 2011 & 17.01 & 47.17 & 388 & 4.64 & 19.27 & 194 \\
\hline & \multicolumn{7}{|c|}{ Within $1 \mathrm{~km}$} \\
\hline & 1997 & 1.54 & 8.22 & 98 & 0.27 & 0.93 & 10 \\
\hline & 1998 & 2.55 & 13.87 & 182 & 4.85 & 16.06 & 122 \\
\hline & 1999 & 2.98 & 16.03 & 144 & 5.18 & 16.87 & 129 \\
\hline & 2000 & 2.21 & 9.88 & 100 & 1.46 & 5.55 & 61 \\
\hline & 2001 & 2.00 & 6.00 & 42 & 1.89 & 5.35 & 49 \\
\hline & 2002 & 1.28 & 5.94 & 67 & 0.29 & 1.43 & 25 \\
\hline & 2003 & 1.49 & 4.61 & 76 & 0.82 & 3.14 & 35 \\
\hline & 2004 & 0.35 & 1.24 & 10 & 0.23 & 0.78 & 5 \\
\hline & 2005 & 1.12 & 2.82 & 20 & 0.65 & 4.00 & 74 \\
\hline & 2006 & 0.21 & 0.93 & 10 & 0.68 & 6.02 & 94 \\
\hline & 2007 & 5.05 & 44.99 & 773 & 7.86 & 75.16 & 1,437 \\
\hline & 2008 & 40.08 & 224.23 & 2,076 & 81.71 & 447.41 & 4,460 \\
\hline & 2009 & 197.22 & 561.79 & 3,679 & 161.14 & 500.04 & 3,896 \\
\hline & 2010 & 710.39 & $1,028.99$ & 6,068 & 242.46 & 509.76 & 3,092 \\
\hline $\begin{array}{l}\mathrm{n}=\text { all homes located W/1n } 1 \mathrm{~km} \\
\text { from host trees }\end{array}$ & 2011 & $2,199.85$ & $4,278.70$ & 33,912 & 527.51 & $1,186.21$ & 7,070 \\
\hline
\end{tabular}

$\mathrm{n}=$ all homes located $\mathrm{w} / \mathrm{in} 1 \mathrm{~km}$ from host trees

given location can have a significant effect on sale price. Based on these figures we create buffers of 1, 5, and $10 \mathrm{~km}$ around each residence in our data, with corresponding binary indicators for fire damage within one, three, and five years of a given sales date. ${ }^{14}$

\footnotetext{
14 We matched home sales with fire damage based on the assumption that the fire season begins on May 1 of each year. Thus, a home that sold before May in a given calendar year is paired with fire events for the preceding calendar year for the 1-year binary indicator. The remaining indicators for temporally further removed fire occurrences are adjusted in analogous fashion.
} 

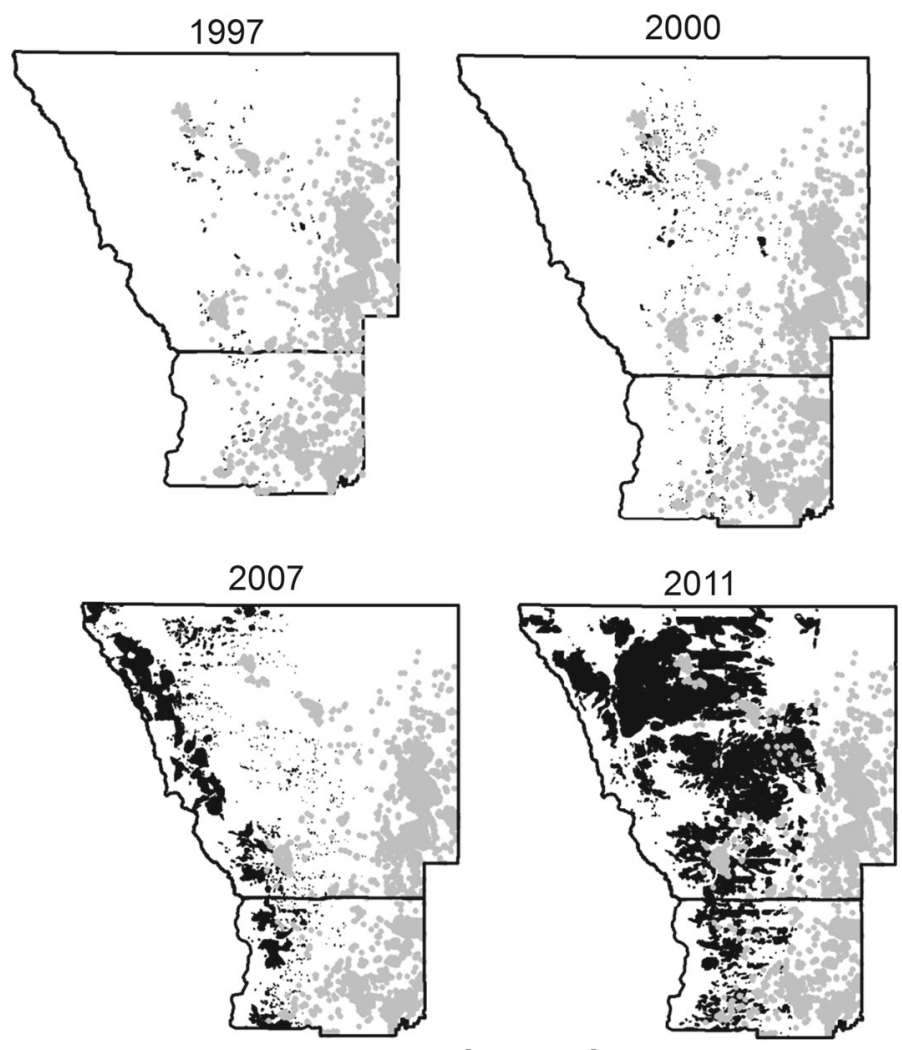

\section{Legend}

- Properties in Sample

Detected MPB Damage via ADS

Fig. 2 MPB expansion 1997-2011. ADS Aerial Detection Survey

\subsection{Estimation Results}

Preliminary regression runs and hypothesis tests revealed that MPB damage via host trees affects home prices only within the $0.1 \mathrm{~km}$ buffer. We thus discard all model components associated with the $1 \mathrm{~km}$ perimeter. This changes vector $\mathbf{h}_{i}$ in (12) to a simple $0 / 1$ scalar for the presence of HTs within the $0.1 \mathrm{~km}$ perimeter. Similarly, wildfire effects proved insignificant for all combinations of distance and lag-time except for the $5 \mathrm{~km} / 5$ year pair. ${ }^{15}$ Accordingly,

\footnotetext{
15 The diminished effect of fires within $1 \mathrm{~km}$ from a home compared to the $5 \mathrm{~km}$ buffer is likely related to the small sample size (less then $1 \%$ of observations) for this distance category. The absence of a stronger effect may also be linked to burn visibility. Stetler et al. (2010) find that fires at any distance from a residence (even 0-5 km) have limited effect on sales prices if the burned area is not visible for a given property. In our case, it is possible that nearby burns are less visible than burns in the $1-5 \mathrm{~km}$ range, depending on the morphology of the local landscape. In addition, home owners may perceive a lower future fire risk to their property if close-by fuel has been consumed by a recent fire, which could counter-act the direct amenity effect of nearby burns. This risk-reducing effect may be absent or even reversed for burns in the $1-5 \mathrm{~km}$ range. Third, there may be a counter-balancing positive amenity effect related to better views that open up in the short run for close-to-home burns (see Hansen and Naughton 2013). Similarly, the insignificant effect of burns within 5
} 
Table 6 Estimation results for HT and fire effects

\begin{tabular}{|c|c|c|c|c|}
\hline & \multicolumn{2}{|c|}{ Larimer } & \multicolumn{2}{|l|}{ Boulder } \\
\hline & Est. & $(\mathrm{SE})$ & Est. & $(\mathrm{SE})$ \\
\hline 1998 (Larimer baseline) & 0.062 & $0.019 * * *$ & - & - \\
\hline 1999 & -0.067 & $0.040 *$ & - & - \\
\hline 2000 & -0.074 & $0.037 * *$ & - & - \\
\hline 2001 & -0.024 & 0.044 & - & - \\
\hline 2002 (Boulder baseline) & -0.079 & $0.042 *$ & -0.127 & $0.029 * * *$ \\
\hline 2003 & -0.086 & $0.040 * *$ & 0.082 & 0.058 \\
\hline 2004 & -0.108 & $0.045 * *$ & 0.036 & 0.056 \\
\hline 2005 & -0.144 & $0.045 * * *$ & 0.015 & 0.057 \\
\hline 2006 & -0.133 & $0.048 * * *$ & 0.027 & 0.063 \\
\hline 2007 & -0.173 & $0.052 * * *$ & 0.086 & 0.067 \\
\hline 2008 & -0.140 & $0.059 * *$ & -0.011 & 0.075 \\
\hline 2009 & -0.213 & $0.063 * * *$ & 0.047 & 0.079 \\
\hline 2010 & -0.253 & $0.061 * * *$ & 0.049 & 0.078 \\
\hline 2011 & -0.313 & $0.066^{* * * *}$ & -0.006 & 0.086 \\
\hline Fire 5 year, $5 \mathrm{~km}$ & 0.017 & 0.013 & -0.042 & $0.011 * * *$ \\
\hline
\end{tabular}

we only retain this single indicator in our final specification. This implies that the vector difference $\mathbf{w}_{i t^{\prime}}-\mathbf{w}_{i t^{0}}$ in (12) reduces to a single indicator, taking the value of -1 if a fire occurred within $5 \mathrm{~km}$ and 5 years preceding time $t^{0}$, but not time $t^{\prime}$, a value of 0 if such a fire occurred preceding neither or both points in time, and a value of 1 if such an event took place preceding time $t^{\prime}$ only.

We estimate separate GLS models for Larimer and Boulder. Estimation results for HT and fire effects are given in Table 6. Results for area-specific intercepts, time trends, and age-depreciation effects are provided in Tables 12 and 13 in "Appendix 2". These appendix tables essentially confirm the basic sample statistics on price development discussed above: In Larimer, prices increase vis-a-vis the baseline year of 1998 until 2005 or 2006 by up to $30-35 \%$, then decline for the remainder of our research period, almost back to baseline levels for some areas. In Boulder, prices decline immediately compared to the 2002 base year, reaching a low of $12-15 \%$ below baseline by 2011 . Age-related depreciation amounts to between 0.5 and $2 \%$ per percentage change in time elapsed between sales, i.e. $t^{\prime}-t^{0}$ in our model notation, relative to time $t^{0} .{ }^{16}$ These results are largely as expected given the recent economic downturn and collapse of the housing market for wide parts of the western US. While they are interesting in their own right, they serve here primarily the purpose of providing a sound and consistent baseline against which MPB effects are to be measured.

Footnote 15 continued

$\mathrm{km}$, but closer in time (within 1 or 3 years of sale) are likely due to small sample size (less than $0.5 \%$ of observations).

16 Area 5 (southern Fort Collins, Loveland) produces a counterintuitive positive effect for age-related depreciation. We attribute this to the many new constructions that occurred in that area during our time span. This can produce a large value for $a_{i},\left(t^{\prime}, t^{0}\right)$, even for pairs of sales that are closely positioned in time, with little to no age-related depreciation. A large enough share of such properties in the data can then produce a positive estimate for the depreciation coefficient $\delta_{s}$. 
We thus turn our attention to the main results in Table 6, which depicts county-specific coefficient estimates for the HT baseline effect $\zeta$, the year-specific HT effects $\beta_{t}$, and the pre-sale wildfire effect $\psi$, as modeled in Eq. (12). As is evident from the table, in Larimer properties within $0.1 \mathrm{~km}$ from host trees fetched a premium over other homes in the baseline year of 1998. However, starting in 1999 this difference reverts and increases in magnitude and significance up to the end of our time horizon. In other words, homes within nearproximity of HTs sold at a progressively increasing discount compared to other residences. By our translating commodity principle, we attribute this relative loss to MPB damage. In stark contrast, as shown in the last three columns of Table 6, the MPB effect appears to have been largely capitalized into home values in Boulder by the baseline year of 2002, as indicated by the significant and negative coefficient estimate for $\zeta$. Relative HT effects remain insignificant for subsequent years. Fire effects, which are captured in the last row of the table, are insignificant for Larimer, but have a significant negative effect on sales prices in Boulder. ${ }^{17}$

\subsection{Predicted Price Trajectories}

There are three price trajectories of interest for our application. First, we establish the baseline price trend by estimating the relative difference in sales price for any year compared to the base year, focusing exclusively on properties outside the $0.1 \mathrm{~km}$ HT perimeter. Econometrically, this effect is given as

$$
\begin{aligned}
m 1_{t} & =E\left[\frac{P_{i t}-P_{i 1}}{P_{i 1}} \mid h_{i}=0\right]=E\left[\frac{P_{i t}}{P_{i 1}} \mid h_{i}=0\right]-1 \\
& =E\left[\exp \left(\xi_{s}+\alpha_{s t}+\psi\left(w_{i t}-w_{i 1}\right)+\delta_{s} a_{i,(t, 1)}+e_{i s,(t, 1)}\right)\right]-1 \\
& =\exp \left(\xi_{s}+\alpha_{s t}+\psi\left(w_{i t}-w_{i 1}\right)+\delta_{s} a_{i,(t, 1)}+\sigma^{2}\right)-1
\end{aligned}
$$

where $E$ is the expectation operator and the addition of 0.5 times the differenced-error variance $2 * \sigma^{2}$ follows from the relationship between the normal distribution of $e_{i s,(t, 1)}$ and the log-normal distribution of $\exp \left(e_{i s,(t, 1)}\right)$ (see e.g. Evans et al. 2000). This term is negligibly small for both the Boulder and Larimer application. In implementing (14) we follow Case et al. (2006) and set the area-specific, non-temporal component of house price appreciation $\xi_{s}$ to zero, as it is not related to any temporal price trajectory. We do the same for the wildfire indicators $w_{i t}-w_{i 1}$ as we want our baseline price index to be untainted by fire effects. Finally, to abstract from any specific age bracket for a given home, and given the close-to-zero estimate of the age depreciation effect for all areas, we also exclude depreciation effects $a_{i,(t, 1)}$ from the computation of $m 1_{t}$. This leaves us with $m 1_{t}=\exp \left(\alpha_{s t}+\sigma^{2}\right)-1$.

Next, we compute the same year-versus-baseline effect for homes with nearby host trees, i.e.

$$
\begin{aligned}
m 2_{t} & =E\left[\frac{P_{i t}-P_{i 1}}{P_{i 1}} \mid h_{i}=1\right]=E\left[\frac{P_{i t}}{P_{i 1}} \mid h_{i}=1\right]-1 \\
& =\exp \left(\xi_{s}+\alpha_{s t}+\zeta+\beta_{t}+\psi\left(w_{i t}-w_{i 1}\right)+\delta_{s} a_{i,(t, 1)}+\sigma^{2}\right)-1
\end{aligned}
$$

Implementing the same adjustments as above with the addition of setting the time-invariant host tree effect $\zeta$ to zero produces $m 2_{t}=\exp \left(\alpha_{s t}+\beta_{t}+\sigma^{2}\right)-1$.

17 Specifically, a home that experienced a recent fire within $5 \mathrm{~km}$ between sales appreciated, on average, by $(\exp (-0.042)-1)=4.1 \%$ less than an otherwise comparable property without a recent fire history. 
The third marginal construct is of central interest to this study. It estimates the relative price differential within a given sales year between homes outside and inside the HT zone. This effect, multiplied by 100 , can be interpreted as the percentage differential in home values due to MPB damage. In this case, time-invariant area effects, as well as fire effects, age depreciation, and the error terms naturally cancel out and we obtain

$$
\begin{aligned}
m 3_{t} & =E\left[\frac{\left(P_{i t} \mid h_{i}=1\right)-\left(P_{i t} \mid h_{i}=0\right)}{P_{i t} \mid h_{i}=0}\right]=E\left[\frac{P_{i t} \mid h_{i}=1}{P_{i t} \mid h_{i}=0}\right]-1 \\
& =\exp \left(\zeta+\beta_{t}\right)-1 .
\end{aligned}
$$

We compute all three price indices for the mountainous areas with host trees in our sample, i.e. areas one and four in Larimer, and area six in Boulder. Area-specific results can be derived for $m 1$ and $m 2$ due to the area-specific generic time effects $\alpha_{s t}$. In contrast, a single set of marginal effects that holds across all areas with HT homes within a given county is produced for $m 3$. We obtain standard errors for all predictions using the simulation approach described in Krinsky and Robb (1986).

Table 7 shows these three price effects for Larimer County. There are subtle but important differences in the general price trends $m 1_{t}$ across the two areas. In area one, prices for MPBunaffected homes increased by up to $34.5 \%$ compared to baseline, reaching a peak in 2005 . Thereafter, prices generally decreased every year, to approximately $28 \%$ above baseline level in 2010. This bubble-like price trajectory is more pronounced in area four, which includes the gateway community of Estes Park mentioned earlier. Specifically, prices peaked in 2006 at $45 \%$ above baseline, and dropped back to $29 \%$ above baseline by 2011 . All price effects (with the exception of that for year 2011 and area 1) are highly significant. The differences in general price trajectories between the two areas stresses the importance of allowing for area-specific price trends. Forcing a common path would amount to a serious specification error that would also lead to biased coefficient estimates for the HT (and thus MPB) effects. ${ }^{18}$

Marginal effects for HT homes vis-a-vis the base year $\left(m 2_{t}\right)$ are shown in columns $7-11$ in Table 7. Price trends for these properties are similar for the first half of our time series, with increases over the base year of 20-21\% (area 1) and close to $27 \%$ (area 4) by the mid-2010s. However, after peaking, prices drop more dramatically than for no-HT homes, reaching levels at or below baseline by 2011. This is a first indication of a gradually intensified MPB effect.

This effect is more directly visible from marginal construct $m 3_{t}$, given in the last block of rows in Table 7. Up until 2005, MPB effects, while carrying a negative sign, remain insignificant. Thereafter, however, damage effects turn significant and increase in severity, up to a MPB induced value loss of $22.2 \%$ in the last year of our series. This pattern is perfectly consistent with the timing and intensification of the MPB expansion as depicted in Fig. 2.

Analogous results for Boulder county's area six are given in Table 8. There, prices for both no-HT and HT homes (first set of rows in Table 8) remained relatively stable compared to the baseline year of 2002, with the exception of a significant price drop of $11-12 \%$ in 2011. Within-year MPB effects $m 3_{t}$, given in the lower part of table, are negative throughout, but spotty in terms of significance. However, the last year shows a significant price drop of $12.5 \%$ for HT homes compared to MPB-unaffected properties.

In summary, our estimation approach via a translating commodity (HT) and a repeat-sales model turned out to be well suited to detect MPB-related value losses, and to map them clearly

18 Estimates from such "erroneously pooled" models are available upon request. 
Table 7 MPB effects Larimer

\begin{tabular}{|c|c|c|c|c|c|c|c|c|}
\hline & \multicolumn{4}{|c|}{ no HT/no HT(1998) } & \multicolumn{4}{|c|}{ HT/HT(1998) } \\
\hline & Est. & $(\mathrm{SE})$ & Low & Up & Est. & $(\mathrm{SE})$ & Low & Up \\
\hline \multicolumn{9}{|l|}{ Area 1} \\
\hline 1999 & 0.072 & $(0.045)$ & -0.012 & 0.164 & 0.003 & $(0.036)$ & -0.065 & 0.075 \\
\hline 2000 & 0.171 & $(0.047)$ & 0.084 & $0.266^{* * *}$ & 0.087 & $(0.039)$ & 0.013 & $0.168 * *$ \\
\hline 2001 & 0.129 & $(0.053)$ & 0.031 & $0.237 * *$ & 0.102 & $(0.041)$ & 0.024 & $0.187 * *$ \\
\hline 2002 & 0.306 & $(0.059)$ & 0.195 & $0.427 * * *$ & 0.207 & $(0.047)$ & 0.119 & $0.303 * * *$ \\
\hline 2003 & 0.313 & $(0.059)$ & 0.203 & $0.433 * * *$ & 0.205 & $(0.047)$ & 0.117 & $0.300 * * *$ \\
\hline 2004 & 0.343 & $(0.069)$ & 0.215 & $0.484 * * *$ & 0.205 & $(0.048)$ & 0.114 & $0.304 * * *$ \\
\hline 2005 & 0.345 & $(0.066)$ & 0.221 & $0.480 * * *$ & 0.164 & $(0.046)$ & 0.077 & $0.259 * * *$ \\
\hline 2006 & 0.257 & $(0.067)$ & 0.132 & $0.396 * * *$ & 0.100 & $(0.048)$ & 0.009 & $0.198 * *$ \\
\hline 2007 & 0.234 & $(0.071)$ & 0.101 & $0.380 * * *$ & 0.038 & $(0.050)$ & -0.055 & 0.139 \\
\hline 2008 & 0.294 & $(0.082)$ & 0.143 & $0.464 * * *$ & 0.125 & $(0.055)$ & 0.022 & $0.239 * *$ \\
\hline 2009 & 0.213 & $(0.084)$ & 0.060 & $0.389 * * *$ & -0.019 & $(0.055)$ & -0.121 & 0.093 \\
\hline 2010 & 0.281 & $(0.090)$ & 0.117 & $0.469 * * *$ & -0.005 & $(0.057)$ & -0.110 & 0.111 \\
\hline 2011 & 0.142 & $(0.086)$ & -0.014 & 0.322 & -0.165 & $(0.052)$ & -0.261 & $-0.057 * * *$ \\
\hline \multicolumn{9}{|l|}{ Area 4} \\
\hline 1999 & 0.076 & (0.039) & 0.003 & $0.155^{*}$ & 0.006 & $(0.027)$ & -0.046 & 0.061 \\
\hline 2000 & 0.195 & (0.039) & 0.121 & $0.275^{* * * *}$ & 0.110 & $(0.028)$ & 0.056 & $0.167 * * *$ \\
\hline 2001 & 0.213 & $(0.049)$ & 0.121 & $0.313 * * *$ & 0.184 & $(0.035)$ & 0.117 & $0.256^{* * *}$ \\
\hline 2002 & 0.279 & $(0.051)$ & 0.184 & $0.382 * * *$ & 0.182 & $(0.035)$ & 0.115 & $0.252 * * *$ \\
\hline 2003 & 0.329 & $(0.048)$ & 0.239 & $0.426 * * *$ & 0.219 & $(0.036)$ & 0.150 & $0.293 * * *$ \\
\hline 2004 & 0.368 & $(0.058)$ & 0.260 & 0.486 *** & 0.228 & (0.038) & 0.156 & $0.305^{* * *} *$ \\
\hline 2005 & 0.419 & $(0.060)$ & 0.306 & $0.543 * * *$ & 0.229 & $(0.040)$ & 0.153 & $0.309 * * *$ \\
\hline 2006 & 0.450 & $(0.067)$ & 0.325 & $0.590 * * *$ & 0.269 & $(0.043)$ & 0.187 & $0.356 * * *$ \\
\hline 2007 & 0.422 & $(0.074)$ & 0.285 & $0.574 * * *$ & 0.196 & $(0.044)$ & 0.112 & $0.286 * * *$ \\
\hline 2008 & 0.335 & $(0.078)$ & 0.190 & $0.497 * * *$ & 0.161 & $(0.048)$ & 0.071 & $0.258 * * *$ \\
\hline 2009 & 0.293 & $(0.082)$ & 0.142 & $0.464 * * *$ & 0.045 & $(0.047)$ & -0.044 & 0.142 \\
\hline 2010 & 0.413 & $(0.084)$ & 0.258 & $0.588 * * *$ & 0.097 & $(0.052)$ & 0.000 & $0.202 *$ \\
\hline 2011 & 0.290 & $(0.082)$ & 0.140 & $0.460 * * *$ & -0.057 & $(0.045)$ & -0.142 & 0.035 \\
\hline
\end{tabular}

HT/no HT

Est.

(SE)

Low

Up

\begin{tabular}{lllll}
\hline All & & & & \\
1999 & -0.004 & $(0.043)$ & -0.085 & 0.083 \\
2000 & -0.012 & $(0.036)$ & -0.080 & 0.062 \\
2001 & 0.039 & $(0.043)$ & -0.043 & 0.127 \\
2002 & -0.017 & $(0.039)$ & -0.089 & 0.063 \\
2003 & -0.024 & $(0.035)$ & -0.091 & 0.048 \\
2004 & -0.045 & $(0.037)$ & -0.114 & 0.030 \\
2005 & -0.078 & $(0.034)$ & -0.142 & $-0.010^{* *}$ \\
2006 & -0.069 & $(0.036)$ & -0.137 & $0.003^{*}$ \\
2007 & -0.105 & $(0.037)$ & -0.175 & $-0.030^{* * *}$ \\
2008 & -0.075 & $(0.044)$ & -0.158 & $0.017^{*}$ \\
2009 & -0.140 & $(0.044)$ & -0.221 & $-0.049^{* * *}$ \\
2010 & -0.174 & $(0.041)$ & -0.250 & $-0.091^{* * *}$ \\
2011 & -0.222 & $(0.043)$ & -0.302 & $-0.135^{* * *}$
\end{tabular}

Est. estimate, $(S E)$ standard error; *, (**), (***) significant at 10\%, (5\%), (1\%) level 
Table 8 MPB effects Boulder

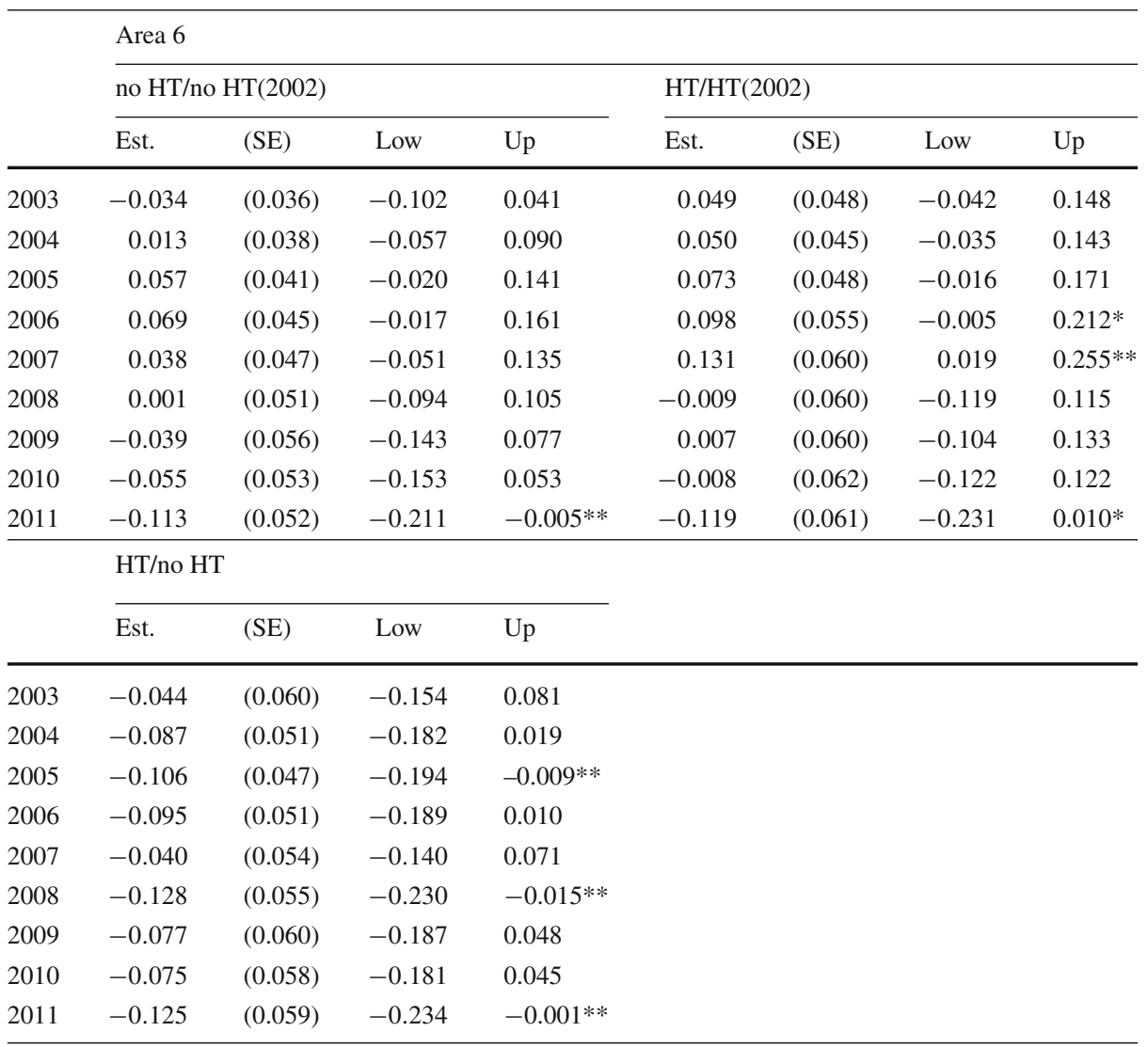

Est. estimate, $(S E)$ standard error

$*,(* *),(* * *)$ significant at $10 \%,(5 \%),(1 \%)$ level

over time. By 2011, MPB-induced losses took substantial proportions. We will translate these percentage differentials into dollar losses per home and for the region as a whole below. ${ }^{19}$

\subsection{Robustness Check: Spokane}

To guard against the possibility that our estimated trend of increasing relative losses for HT homes simply reflects changing preferences of home buyers over the years, we repeat our analysis for a "control area" with similar population size and abundant host trees, but no documented MPB damage. Specifically, we estimate our model in (12) for the city of Spokane, Washington. Assuming home owner's preferences with respect to "trees" and woody surroundings in Spokane are at least somewhat similar to those for our Front Range communities, price trends in Spokane for no-HT homes and HT homes should move in equal or at least parallel fashion in absence of increasing "tree aversion." In other words, a

\footnotetext{
19 As is the case with most hedonic studies, our model cannot distinguish between actually experienced and expected MPB effects on home prices. Our estimated price trajectories and loss estimates include both components. However, since our time series of home sales starts well before the explosive expansion of the MPB, we are confident that our estimates captures the full MPB effect, that is actual plus expected.
} 
homogeneous price trajectory for no-HT and HT properties in Spokane would rule out a general and widespread shift in preference away from trees and towards open land in the mountainous west. This, in turn, would lend additional credibility to our interpretation of no-HT/HT price differentials in Colorado as attributable to MPB damage.

The Spokane data comprises 23,841 observations for 18,428 homes with repeat sales between 1997 and 2011. We estimate the Spokane RSM using the exact same variables as for our main analysis. We allow for separate price trends for three different markets, but continue to specify a common annual series of HT effects. Estimation results for the latter are given in Appendix Table $14 .^{20}$ As is evident from the table, starting with the base year of 1997, HT effects are-at worst - close to zero and insignificant. In fact, homes with nearby host trees actually fetch a highly significant price premium of 2-3\% for several years in our series.

Clearly, there is no indication of a price discount for HT homes, let alone one that is progressively increasing over time. The Spokane counter-study thus provides strong support for our interpretation of value losses in the Colorado Front Range as MPB-induced.

\subsection{Loss Predictions and Policy Implications}

To translate the percentage losses discussed above into 2011 currency for HT homes in areas one, four, and six, we proceed in three conceptual steps. First, we compute the year-specific counterfactual price that each home would have received in absence of MPB damage, using

$$
\tilde{P}_{i t}=\frac{P_{i t}}{1+m 3_{t}},
$$

where $P_{i t}$ is the observed price, and $m 3_{t}$ is defined in (16). Second, we translate this "HT purged" value into the price the same home would have sold for in the final year $T$ (2011 in our case) via

$$
\hat{P}_{i, T}=\tilde{P}_{i t}\left(1+\kappa_{s, t, T}\right),
$$

where $\kappa_{s, t, T}=\exp \left(\alpha_{s, T}-\alpha_{s t}+\sigma^{2}\right)-1$, and the $\alpha$-terms are the area and year-specific generic price effects as given in (12). For Boulder, where estimated wildfire effects are significant, we also control for forest fires that may have occurred (or subsided) between any year $t$ and 2011 by adding (or subtracting) the wildfire coefficient $\psi$ in the exponent of $\kappa_{s, t, T}$. These first two steps yield the predicted sales price in 2011 for all HT-homes in our sample, purged of any MPB-induced value losses. In step three, we then simply apply the MPBinduced percentage losses for 2011, as reported in Tables 7 and 8, i.e. $-22.2 \%$ for Larimer and $-12.5 \%$ for Boulder. We implement these three steps for every HT property in our repeatsales data, as well as for all remaining single-sale homes located in the HT zone that are not included in our principal analysis. Importantly, throughout all three steps we carry forward the standard errors for all coefficients involved to generate accurate uncertainty bounds for our final predictions. The details for these derivations are given in "Appendix 2".

Predicted losses per home and aggregate losses for various sub-sets of our data are given in Table 9. The first row of the table shows the number of properties that are located within $0.1 \mathrm{~km}$ from host trees for each county and the entire region. Within each county, the first column refers to all such homes, including single-sale properties. The second column refers to all HT homes that were actually included in our RSM (i.e. those with multiple sales during our research period). On a per-home basis, MPB induced losses amount to $\$ 70,000$ for the broader sample in Larimer, and \$61,000 for Boulder. However, while the lower confidence bound for Larimer is still a sizable $\$ 41,000$, the lower bound for Boulder is near-zero.

$\overline{20}$ The full set of results for Spokane are available upon request. 
Table 9 Predicted losses for homes with host trees within $0.1 \mathrm{~km}$

\begin{tabular}{|c|c|c|c|c|c|c|}
\hline & \multicolumn{2}{|l|}{ Larimer* } & \multicolumn{2}{|l|}{ Boulder** } & \multicolumn{2}{|l|}{ Both } \\
\hline & All homes & RS homes & All homes & RS homes & All homes & RS homes \\
\hline \# homes & 1,147 & 366 & 817 & 196 & 1,964 & 562 \\
\hline \multicolumn{7}{|c|}{ Loss per home $(\$ 000 \mathrm{~s})$} \\
\hline Estimate & 76 & 70 & 61 & 56 & - & - \\
\hline Lower & 41 & 38 & 0 & 0 & - & - \\
\hline Upper & 115 & 104 & 127 & 115 & - & - \\
\hline \multicolumn{7}{|c|}{ Total loss, all homes $(\$ 000 \mathrm{~s})$} \\
\hline Estimate & 87,277 & 25,439 & 49,637 & 10,911 & 136,913 & 36,350 \\
\hline Lower & 47,374 & 13,913 & 407 & 91 & 47,781 & 14,004 \\
\hline Upper & 131,614 & 38,115 & 103,434 & 22,491 & 235,048 & 60,605 \\
\hline
\end{tabular}

Lower (upper) = lower (upper) bound for a $95 \%$ confidence interval

* Includes home with most recent sale in or after 1998

** Includes homes with most recent sale in or after 2002

The wider confidence bounds for predicted losses for Boulder are directly related to the lack of significant for most year-specific marginal HT effects, as shown in Table 8.

Aggregating over the entire sample of HT homes produces a total estimated value loss of close to $\$ 90$ million for Larimer with a lower bound of close to $\$ 50$ million, and an upper bound of over $\$ 130$ million. For Boulder, the approximate point estimate, lower, and upper bound amount to $\$ 50$ million, $\$ 400,000$, and $\$ 100$ million, respectively. Given that our cleaning steps during data preparation reduced sample sizes by $40-50 \%$ compared to the total housing stock of single-family residences in each county, these estimates are probably best interpreted as conservative lower bounds for county-wide figures.

From a fiscal policy perspective, these losses can be directly translated into foregone property taxes. Focusing on Larimer, for which our loss estimates exhibit a relatively high degree of precision, we can convert reductions in home values into a decrease in collected taxes by multiplying the estimates in Table 9 by a factor of $0.6 \%$, the typical district-level tax rate in 2011 for communities in the HT zone such as Estes Park. ${ }^{21}$ Focusing again on all HT homes, this yields an estimated per-home loss in annual property taxes compared to the amount that would have been collected in absence of the MPB infestation of $\$ 454$ (with bounds of $\$ 247$ and $\$ 685$ ), and an aggregate annual reduction in tax collections of $\$ 521,000$ (with bounds of $\$ 283,000$ and $\$ 786,000$ ). Given that the MPB damage is irreversible and will likely continue to worsen over future years, these annual shortfalls have to be considered as perpetual lower bounds for losses in property tax income. This will strain municipal budgets of heavily-impacted communities such as Estes Park in area 4 for the foreseeable future.

The implications of our results for forest policy are less clear-cut. There are no known large-scale interventions that could slow down or halt the infestation. On an individual basis, trees can be protected by applying insecticides, but this approach is infeasible on a landscapelevel scale and in remote, difficult-to-access areas. Our results may serve to foreshadow

21 This rate is composed of a county-wide conversion factor of 0.0796 that translates assessed market value into "tax-assessed value"(Larimer County Treasurer 2013a) We found the assessed market value to be generally very close to observed sales prices for homes sold in 2011 in our data. Thus, implicitly departing from our predicted sales prices for 2011 before assessing these tax rates appears justified. A district-specific "mill levy" is then applied to this taxable amount. In 2011, mill levies for Estes Park varied between 7 and $8 \%$ for most tax districts (Larimer County Assessor 2013b). We use a mill levy of $7.5 \%$ for our calculations. 
expected economic losses in to-date unaffected areas, should they be reached by the spreading infestation. This, in turn, may provide input into a possible re-formulation of forest policy to avoid vast expanses of similar-aged pine forests in the future. That appears to be one avenue within the realm of human control.

\section{Conclusion}

We introduce a simple and low-cost approach to the estimation of real estate capitalization rates of difficult-to-measure environmental changes over time via a translating amenity (TA). The ideal TA is invariant over time, and enters both the utility function of home owners and the hedonic price surface of local property markets. It is readily observed by property owners, and straightforward to measure by the analyst via modern GIS tools. Most importantly, it constitutes the sole link between owners' preferences and the environmental amenity of interest. This is akin to the weak complementarity relationship between site quality and visitation trips in recreation demand analyses. We show that the the TA can be utility-theoretically motivated as being directly related to the implicit price of the unobserved quality when used in a repeat sales (RS) context.

In our application the TA is provided via host trees near a given residence, which, in turn, are impacted by the Mountain Pine Beetle, the primary environmental commodity of interest. Using a state-of-the-art repeat sales model we illustrate how temporal changes in the effect of host trees on home values can be interpreted as the capitalization effect of a progressing MPB infestation. Controlling for sub-area specific real estate price trajectories, wildfire events, and age-related depreciation, we estimate this effect to amount to tens of millions of dollars for the two counties we studied. This has perpetual implications for collected property taxes in heavily infested communities.

We envision this translating amenity approach to be useful in a variety of other property valuation contexts when the policy-relevant environmental quality of interest is measured with large spatial and/or temporal gaps or when such measurements simply do not exist. First, given the continued expansion of the MPB epidemic, there will likely be a need for future hedonic studies to assess its impact on real estate markets. Naturally, the TA is also suitable for any other applications involving different forest pests and diseased trees. Second, the TA method will likely find future applicability in the hedonic valuation of water quality. As has been pointed out numerous times by scientists continued climate change will affect water temperature and quality, and thus the well-being of hydrological ecosystems for bodies of surface water around the world (Murdoch et al. 2000; Daufresne and Boët 2007; Whitehead et al. 2009). In many cases where water quality may affect nearby home values it will likely be infeasible to collect updated, neighborhood-specific hydrological samples. The TA method may be an attractive solution in such applications, especially in dense and lively housing markets.

\section{Appendix 1}

See Tables 10, 11, 12, 13 and 14. 
Table 10 Price statistics by area, Larimer (2011 dollars, units of 000s)

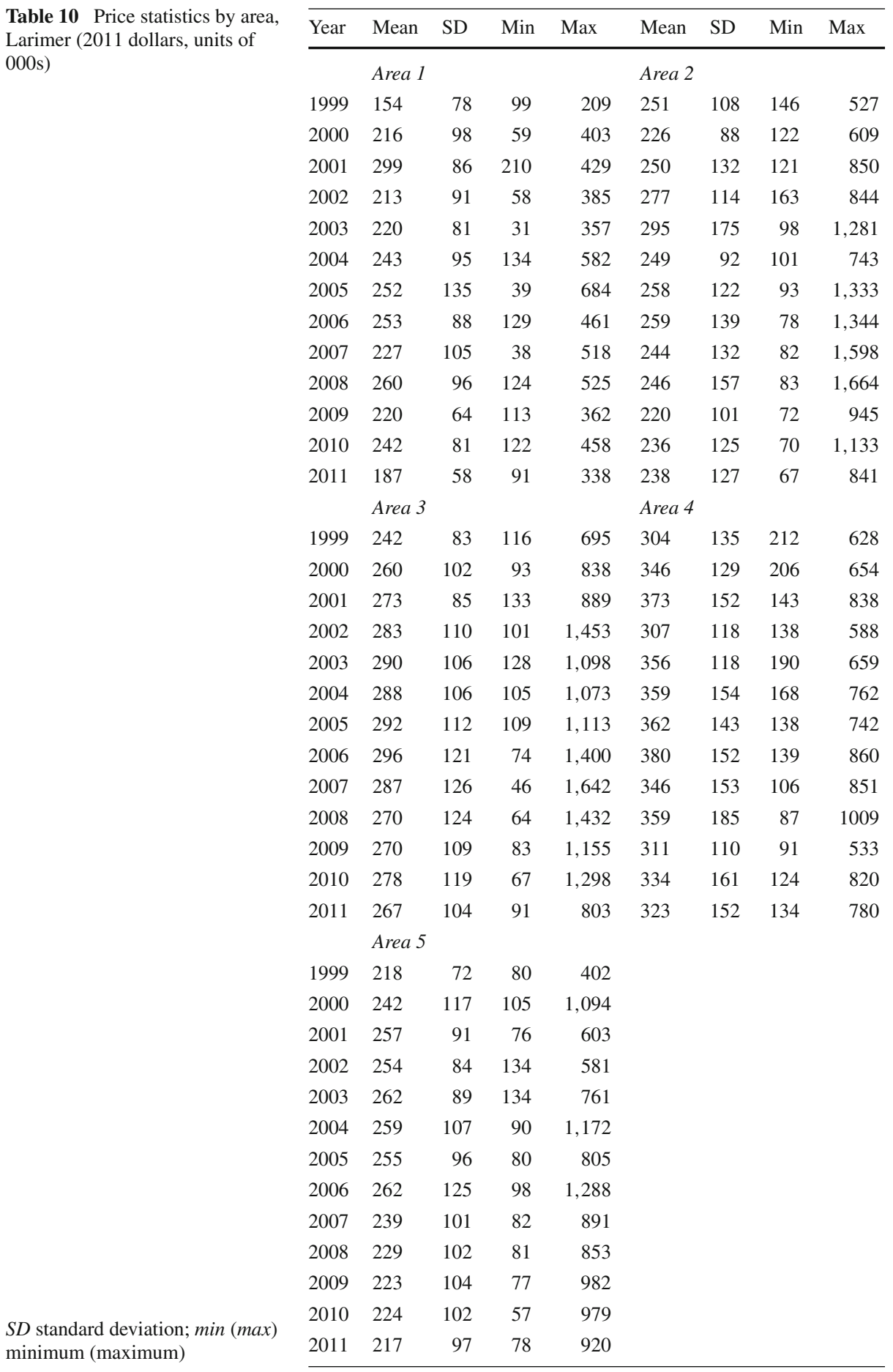


Table 11 Price statistics by area, Boulder (2011 dollars, units of 000s)

SD standard deviation; $\min (\max )$ minimum (maximum)

\begin{tabular}{|c|c|c|c|c|c|c|c|c|}
\hline \multirow[t]{2}{*}{ Year } & \multicolumn{4}{|c|}{ Area 6} & \multicolumn{4}{|c|}{ Area 7} \\
\hline & Mean & SD & Min & Max & Mean & SD & Min & Max \\
\hline 2003 & 862 & 420 & 489 & 1,464 & 438 & 189 & 193 & 1,061 \\
\hline 2004 & 621 & 241 & 274 & 1,284 & 415 & 259 & 119 & 2,797 \\
\hline 2005 & 622 & 264 & 216 & 1,419 & 416 & 237 & 126 & 3,278 \\
\hline 2006 & 730 & 361 & 224 & 2,019 & 404 & 232 & 106 & 2,296 \\
\hline 2007 & 750 & 493 & 162 & 3,051 & 384 & 238 & 82 & 3,078 \\
\hline 2008 & 764 & 354 & 146 & 2,007 & 356 & 208 & 73 & 2,293 \\
\hline 2009 & 616 & 302 & 144 & 1,524 & 348 & 200 & 82 & 3,045 \\
\hline 2010 & 591 & 273 & 157 & 1,329 & 364 & 219 & 69 & 2,189 \\
\hline 2011 & 627 & 436 & 108 & 2,500 & 370 & 231 & 75 & 2,600 \\
\hline
\end{tabular}

Table 12 Additional estimation results, Larimer

\begin{tabular}{|c|c|c|c|c|c|c|}
\hline & Est. & $(\mathrm{SE})$ & Est. & $(\mathrm{SE})$ & Est. & $(\mathrm{SE})$ \\
\hline Intercept & $\begin{array}{c}\text { Area } 1 \\
-0.088\end{array}$ & $(0.025)^{* * *}$ & $\begin{array}{c}\text { Area } 2 \\
-0.041\end{array}$ & $(0.005)^{* * *}$ & $\begin{array}{c}\text { Area } 3 \\
-0.008\end{array}$ & $(0.003) * * *$ \\
\hline 1999 & 0.070 & $(0.042)^{*}$ & 0.065 & $(0.013) * * *$ & 0.047 & $(0.005)^{* * *}$ \\
\hline 2000 & 0.158 & $(0.040)^{* * *}$ & 0.128 & $(0.013)^{* * *}$ & 0.113 & $(0.005) * * *$ \\
\hline 2001 & 0.122 & $(0.047)^{* * *}$ & 0.193 & $(0.012)^{* * *}$ & 0.180 & $(0.005)^{* * * *}$ \\
\hline 2002 & 0.267 & $(0.045)^{* * *}$ & 0.236 & $(0.012)^{* * * *}$ & 0.213 & $(0.005)^{* * * *}$ \\
\hline 2003 & 0.273 & $(0.045)^{* * *}$ & 0.255 & $(0.013) * * *$ & 0.213 & $(0.005)^{* * *}$ \\
\hline 2004 & 0.295 & $(0.051) * * *$ & 0.248 & $(0.013) * * *$ & 0.217 & $(0.005)^{* * *}$ \\
\hline 2005 & 0.296 & $(0.049) * * *$ & 0.253 & $(0.013) * * *$ & 0.212 & $(0.005)^{* * *}$ \\
\hline 2006 & 0.229 & $(0.054)^{* * * *}$ & 0.237 & $(0.014)^{* * *}$ & 0.198 & $(0.006)^{* * *}$ \\
\hline 2007 & 0.210 & $(0.057)^{* * *}$ & 0.166 & $(0.014)^{* * * *}$ & 0.156 & $(0.006)^{* * * *}$ \\
\hline 2008 & 0.258 & $(0.063)^{* * *}$ & 0.124 & $(0.016)^{* * *}$ & 0.089 & $(0.007)^{* * *}$ \\
\hline 2009 & 0.193 & $(0.069) * * *$ & 0.115 & $(0.016)^{* * *}$ & 0.103 & $(0.007)^{* * *}$ \\
\hline 2010 & 0.248 & $(0.070)^{* * *}$ & 0.116 & $(0.017) * * *$ & 0.093 & $(0.007) * * *$ \\
\hline 2011 & 0.133 & $(0.075)^{*}$ & 0.073 & $(0.018)^{* * * *}$ & 0.077 & $(0.008)^{* * * *}$ \\
\hline \multirow[t]{2}{*}{ Age depr. } & 0.000 & $(0.007)$ & -0.023 & $(0.001)^{* * *}$ & -0.005 & $(0.001)^{* * *}$ \\
\hline & Area 4 & & Area 5 & & & \\
\hline Intercept & -0.072 & $(0.024) * * *$ & 0.008 & $(0.004)^{* * *}$ & & \\
\hline 1999 & 0.073 & $(0.036)^{* *}$ & 0.058 & $(0.007) * * *$ & & \\
\hline 2000 & 0.179 & $(0.033) * * *$ & 0.120 & $(0.007) * * *$ & & \\
\hline 2001 & 0.193 & $(0.040)^{* * *}$ & 0.178 & $(0.008) * * *$ & & \\
\hline 2002 & 0.246 & $(0.039) * * *$ & 0.207 & $(0.008) * * *$ & & \\
\hline 2003 & 0.285 & $(0.036) * * *$ & 0.196 & $(0.008) * * *$ & & \\
\hline 2004 & 0.313 & $(0.042) * * *$ & 0.192 & $(0.008) * * *$ & & \\
\hline 2005 & 0.350 & $(0.042) * * *$ & 0.173 & $(0.008)^{* * * *}$ & & \\
\hline 2006 & 0.372 & $(0.047)^{* * *}$ & 0.151 & $(0.009)^{* * *}$ & & \\
\hline 2007 & 0.352 & $(0.052) * * *$ & 0.079 & $(0.010)^{* * * *}$ & & \\
\hline 2008 & 0.289 & $(0.059) * * *$ & -0.013 & $(0.011)$ & & \\
\hline 2009 & 0.257 & $(0.063)^{* * *}$ & -0.009 & $(0.011)$ & & \\
\hline 2010 & 0.345 & $(0.059) * * *$ & -0.025 & $(0.011)^{* *}$ & & \\
\hline 2011 & 0.254 & $(0.063)^{* * *}$ & -0.062 & $(0.012)^{* * *}$ & & \\
\hline Age depr. & -0.005 & $(0.005)$ & 0.003 & $(0.001)^{* * *}$ & & \\
\hline
\end{tabular}

Est. estimate, (SE) standard error, Age. depr age-related depreciation $*,(* *),(* * *)$ significant at $10 \%,(5 \%),(1 \%)$ level 
Table 13 Additional estimation results, Boulder

\begin{tabular}{llllll}
\hline & Area 6 & & & Area 7 & \\
\cline { 2 - 3 } \cline { 5 - 6 } & Est. & $(\mathrm{SE})$ & & Est. & $(\mathrm{SE})$ \\
\hline Intercept & 0.046 & $(0.026)^{*}$ & -0.017 & $(0.005)^{* * *}$ \\
2003 & -0.034 & $(0.038)$ & -0.028 & $(0.007)^{* * *}$ \\
2004 & 0.013 & $(0.037)$ & -0.020 & $(0.007) * * *$ \\
2005 & 0.056 & $(0.039)$ & -0.002 & $(0.007)$ \\
2006 & 0.067 & $(0.042)$ & -0.011 & $(0.008)$ \\
2007 & 0.037 & $(0.046)$ & -0.056 & $(0.009)^{* * *}$ \\
2008 & 0.001 & $(0.051)$ & -0.111 & $(0.010) * * *$ \\
2009 & -0.039 & $(0.058)$ & -0.105 & $(0.010) * * *$ \\
2010 & -0.057 & $(0.056)$ & -0.116 & $(0.011)^{* * *}$ \\
2011 & -0.120 & $(0.059) * *$ & -0.146 & $(0.012)^{* * *}$ \\
Age depr. & -0.004 & $(0.005)$ & -0.005 & $(0.001)^{* * *}$ \\
\hline
\end{tabular}

Table 14 Estimation results for HT effects, Spokane

\begin{tabular}{lrl}
\hline & \multicolumn{1}{c}{ Est. } & $(\mathrm{SE})$ \\
\hline Baseline & -0.001 & 0.003 \\
1998 & -0.008 & 0.009 \\
1999 & 0.005 & 0.009 \\
2000 & 0.015 & $0.009 *$ \\
2001 & 0.013 & 0.009 \\
2002 & 0.019 & $0.009 * *$ \\
2003 & 0.019 & $0.009 * *$ \\
2004 & 0.028 & $0.009 * * *$ \\
2005 & 0.035 & $0.009 * * *$ \\
2006 & 0.031 & $0.010 * * *$ \\
2007 & 0.015 & 0.011 \\
2008 & 0.019 & 0.012 \\
2009 & 0.007 & 0.012 \\
2010 & -0.004 & 0.013 \\
2011 & 0.015 & 0.014 \\
\hline
\end{tabular}

\section{Appendix 2: Details for Loss Predictions}

In step one we seek the counterfactual price of a home near host trees in absence of any MPB effects, for each year of our series. From Eq. (16) we have

$$
E\left[\frac{P_{i t} \mid h_{i}=1}{P_{i t} \mid h_{i}=0}\right]=1+m 3_{t}=\exp \left(\zeta+\beta_{t}\right)
$$

For a given home in the HT zone with observed price $P_{i t}$ we then obtain

$$
\tilde{P}_{i t}=E\left[P_{i t} \mid h_{i}=0\right]=\frac{P_{i t}}{1+m 3_{t}}=\frac{P_{i t}}{\exp \left(\zeta+\beta_{t}\right)}
$$


Next, we compute the pure price differential between the final time period $T$ and year $t$ in absence of any MPB disturbance. Following the derivation in (14) we obtain

$$
\begin{aligned}
\kappa_{s, t, T} & =E\left[\frac{P_{i T}-P_{i t}}{P_{i t}} \mid h_{i}=0\right]=E\left[\frac{P_{i T}}{P_{i t}} \mid h_{i}=0\right]-1 \\
& =E\left[\exp \left(\xi_{s}+\alpha_{s T}-\alpha_{s t}+\psi\left(F_{i T}-F_{i t}\right)+\delta_{s} a_{i,(T, t)}+e_{i s,(T, t)}\right)\right]-1 \\
& =\exp \left(\xi_{s}+\alpha_{s T}-\alpha_{s t}+\psi\left(F_{i T}-F_{i t}\right)+\delta_{s} a_{i,(T, t)}+\sigma^{2}\right)-1
\end{aligned}
$$

Ignoring the time-invariant spatial index, as well as fire and depreciation effects leaves $\kappa_{s, t, T}=\exp \left(\alpha_{s T}-\alpha_{s t}+\sigma^{2}\right)-1$. The counterfactual price of affected home $i$ in absence of any MPB impacts and projected to the final year $T$ can then be computed as

$$
\begin{aligned}
\tilde{P}_{i T} & =\tilde{P}_{i t}\left(1+\kappa_{s, t, T}\right) \\
& =P_{i t} \frac{1+\kappa_{s, t, T}}{1+m 3_{t}} \\
& =P_{i t} \exp \left(\alpha_{s T}-\alpha_{s t}-\zeta-\beta_{t}+\sigma^{2}\right)=P_{i t} \rho_{s, t, T}
\end{aligned}
$$

We implement these predictive steps via simulation along the lines proposed by Krinsky and Robb (1986) as follows: We take 100,000 draws of each contributing coefficient in the last line of (22) from their respective finite sample distribution, taking account of all involved covariances. For each draw we then compute $\rho_{s, t, T}$ as given in the last line of (22) and capture the mean, 2.5th, and 97.5th percentile of the resulting empirical distribution. We repeat this procedure for every $t \neq T$. We then multiply observed price $P_{i t}$ by the appropriate year-specific mean conversion factor [term $\rho_{s, t, T}$ in the last line of (22)] as well as by the confidence bounds for all HT homes in our data. This produces an estimate and confidence bounds for the predicted "MPB purged" sales price $\tilde{P}_{i T}$ in 2011.

In a final step, we then apply the point estimate of MPB loss in 2011 (see Tables 7, 8) to each predicted mean price, the lower bound of the MPB loss estimate to each upper bound for predicted price, and the upper bound of MPB loss estimate to each lower bound for predicted price to derive a point estimate and confidence bounds for predicted MPB losses, in 2011 dollars, for each property.

\section{References}

Anselin L, Lozano-Gracia N (2008) Errors in variables and spacial effects in hedonic house price models of ambient air quality. Empir Econ 34:5-34

Bentz B, Jacques R, Fettig C, Hansen E, Hayes J, Hicke J, Kelsey R, Negrn J, Seybold S (2010) Climate change and bark beetles of the Western United States and Canada: direct and indirect effects. Bioscience 60:602-613

Boyle K, Kuminoff N, Zhang C, Devanney M, Bell K (2010) Does a property-specific environmental health risk create a "neighborhood" housing price stigma? Arsenic in private well water. Water Resour Res 46(W03):507

Carbone J, Hallstrom D, Smith V (2006) Can natural experiments measure behavioral responses to environmental risk? Environ Resour Econ 33:273-297

Carroll A, Taylor S, Régnière J, Safranyik L (2004) Effects of climate change on range expansion by the mountain pine beetle in British Columbia. In: Shore T, Brooks J, Stone J (eds) Mountain pine beetle symposium: challenges and solutions, October 30-31, 2003, Kelowna, British Columbia, Natural Resources Canada, Canadian Forest Service, Pacific Forestry Center, Information report BC-X-399, pp 223-232

Case B, Colwell P, Leishman C, Watkins C (2006) The impact of environmental contamination on condo prices: a hybrid repeat-sales/hedonic approach. Real Estate Econ 34:77-107 
Chau K, Wong S, Yiu C (2005) Adjusting for nonlinear age effects in the repeat sales index. J Real Estate Finance Econ 31:137-153

Cho SH, Roberts R, Kim S (2011) Negative externalities on property values resulting from water impairment: the case of the Pigeon River watershed. Ecol Econ 70:2390-2399

Dastrup S, Graff Zivin J, Costa D, Kahn M (2012) Understanding the solar home price premium: electricity generation and "green" social status. Eur Econ Rev 56:961-973

Daufresne M, Boët P (2007) Climate change impacts on structure and diversity of fish communities in rivers. Glob Change Biol 13:2467-2478

Eidenshink J, Schwind B, Brewer K, Zhu Z, Quayle B, Howard S (2007) A project for monitoring trends in burn severity. Fire Ecol 3:3-21

Evans M, Hastings N, Peacock B (2000) Statistical distributions, 3rd edn. Wiley, New York

Federal Highway Administration (2014) Highway traffic and construction noise-regulation and guidance. http://www.fhwa.dot.gov/environment/noise/regulations_and_guidance/. Accessed 27 May 2014

Francke M (2010) Repeat sale index for thin markets: a structured time series approach. J Real Estate Finance Econ 41:24-52

Freeman A (2003) The measurement of environmental and resource values, 2nd edn. Resources for the Future, Washington

Goetzmann W, Spiegel M (1995) Non-temporal components of residential real estate appreciation. Rev Econ Stat 77:199-206

von Haefen R (2007) Empirical strategies for incorporating weak complementarity into consumer demand models. J Environ Econ Manag 54:15-31

Hansen W, Naughton H (2013) The effects of a spruce bark beetle outbreak and wildfires on property values in the wildland-urban interface of south-central Alaska, USA. Ecol Econ 96:141-154

Holmes T, Murphy E, Bell K (2006) Exotic forest insects and residential property values. Agric Resour Econ Rev 35(1):155-166

Holmes T, Murphy E, Bell K, Royle D (2010) Property value impacts of hemlock wooly adelgid in residential forests. For Sci 56:529-540

Kim C, Phipps T, Anselin L (2003) Measuring the benefits of air quality improvement: a spatial hedonic approach. J Environ Econ Manag 45:24-39

Kovacs K, Holmes T, Englin J, Alexander J (2011) The dynamic response of housing values to a forest invasive disease: evidence from a sudden oak death infestation. Environ Resour Econ 49:445-471

Krinsky I, Robb A (1986) On approximating the statistical properties of elasticities. Rev Econ Stat 68:715-719

Larimer County Assessor (2013b) 2011 Larimer County mill levies. http://www.co.larimer.co.us/assessor/ 2011 milllevies_authority.pdf. Accessed 8 Apr 2013

Larimer County Treasurer (2013a) Common questions about property taxes. http://www.larimer.org/treasurer/ frequent.htm. Accessed 8 Apr 2013

Leggett C, Bockstael N (2000) Evidence of the effect of water quality on residential land prices. J Environ Econ Manag 39:121-144

Man G (2012) Major forest insect and disease conditions in the United States: 2011. Technical report FS-1000, United States Department of Agriculture, Forest Service

Mendelsohn R, Hellerstein D, Huguenin M, Unsworth R, Brazee R (1992) Measuring hazardous waste damages with panel data models. J Environ Econ Manag 22:259-271

Murdoch P, Baron J, Miller T (2000) Potential effects of climate change on surface-water quality in North America. J Am Water Resour Assoc 36:347-366

National Interagency Fire Center (2012) Total wildland fires and acres (1960-2009). http://www.nifc.gov/ fireInfo/fireInfo_stats_totalFires.html. Accessed 3 Apr 2013

Neill H, Hassenzahl D, Assane D (2007) Estimating the effect of air quality: spatial versus traditional hedonic models. South Econ J 73:1088-1111

Palmquist R (1980) Alternative techniques for developing real estate price indexes. Rev Econ Stat 62:442-448

Palmquist R (1982) Measuring environmental effects on property values without hedonic regressions. J Urban Econ 11:333-347

Palmquist R (1991) Hedonic methods. In: Braden J, Kolstad C (eds) Measuring the demand for environmental quality. Elsevier, North Holland, pp 71-120

Palmquist R (2005) Property value models. In: Mäler KG, Vincent J (eds) Handbook of environmental economics, vol II. Elsevier, North Holland, pp 763-819

Phaneuf DJ, Smith V, Palmquist R, Pope J (2008) Integrating property value and local recreation models to value ecosystem services in urban watersheds. Land Econ 84(3):361-381

Pope $\mathbf{J}$ (2008) Buyer information and the hedonic: the impact of a seller disclosure on the implicit price for airport noise. J Urban Econ 63:498-516 
Price J, McCollum D, Berrens R (2010) Insect infestation and residential property values: a hedonic analysis of the mountain pine beetle epidemic. For Policy Econ 12:415-422

Ruefenacht B, Finco M, Nelson M, Czaplewski R, Helmer E, Blackard J, Holden G, Lister A, Salajanu D, Weyermann D, Winterberger K (2008) Conterminous U.S. and Alaska forest type mapping using forest inventory and analysis data. Photogramm. Eng. Remote Sens 74(11):1379-1388

Sims C, Aadland D, Finnoff D (2010) A dynamic bioeconomic analysis of mountain pine beetle epidemics. J. Econ. Dyn. Control 34:2407-2419

Stetler K, Tyron V, Calkin D (2010) The effects of wildfire and environmental amenities on property values in Northwest Montana, USA. Ecol Econ 69:2233-2243

US Environmental Protection Agency (2014a) Chesapeake Bay TMDL. http://www.epa.gov/chesape akebaytmdl/. Accessed May 272014

US Environmental Protection Agency (2014b) Particulate matter (PM) standards. http://www.epa.gov/ttn/ naaqs/standards/pm/s_pm_index.html. Accessed 27 May 2014

US Environmental Protection Agency (2014c) Sulfur dioxide (SO2) primary national ambient air quality standards. http://www.epa.gov/ttn/naaqs/standards/so2/s_so2_index.html. Accessed May 272014

US Environmental Protection Agency (2014d) Watershed priorities, Lake Tahoe, CA \& NV. http://www.epa. gov/region9/water/watershed/tahoe/tools-tmdl.html\#tmdl. Accessed May 272014

USDA Forest Service (2012a) Forest type groups of the United States. http://fsgeodata.fs.fed.us/rastergateway/ forest_type/conus_forest_type_group_metadata.php. Accessed Apr 32013

USDA Forest Service (2012b) Monitoring trends in burn severity. http://www.mtbs.gov/documents_ references.html. Accessed 4 Apr 2013

USDA Forest Service (2012c) Wildland fire decision support system. https://wfdss.usgs.gov/wfdss/WFDSS Data.shtml. Accessed 4 Apr 2013

Whitehead P, Wilby R, Battarbee R, Kernan M, Wade A (2009) A review of potential impacts of climate change on surface water quality. Hydrol Sci 54:101-123

Wooldridge JM (2012) Econometric analysis of cross section and panel data, 2nd edn. MIT Press, Cambridge 